\title{
Bearing failure in stainless steel bolted connections
}

\author{
E L Salih, L Gardner and D A Nethercot
}

\begin{abstract}
Although the mechanical behaviour of stainless steel and carbon steel differs significantly, design provisions for stainless steel connections in current standards are essentially based on the rules for carbon steel. For bolted connections, the design resistances in EN 1993-1-4 and the SCI/Euro Inox Design Manual for Structural Stainless Steel are based on those in EN 1993-1-8 and EN 1993-1-3 with only some minor modifications. In this paper, an investigation into the bearing behaviour of stainless steel connections between both thick and thin plates has been conducted. Numerical models for previously tested specimens in austenitic and ferritic stainless steel have been developed and validated. The validated models were then used to perform parametric studies to investigate the key variables affecting the bearing failure of bolted connections; these include edge distance $e_{2}$, end distance $e_{1}$ and plate thickness $t$. The investigation showed the deformation behaviour of stainless steel connections to be somewhat different from that of carbon steel connections, with stainless steel exhibiting pronounced strain hardening. However, the locations of fracture initiation obtained from the numerical models matched those observed during experimental studies of both carbon steel and stainless steel connections and this feature has been used as the basis for defining a consistent, strength based criterion of failure. The results of the parametric studies have been utilised as the basis for design provisions for bearing failure in stainless steel bolted connections that cover both the ultimate and the serviceability limit states and which are both more economic and more straightforward than the present EC3 provisions.
\end{abstract}




\section{Keywords:}

Bearing failure, Bolted connections, Eurocode 3, Finite element modelling, Joints, Numerical modelling, Stainless steel.

\section{Introduction}

Although its usage in structural situations is still only a small fraction of that of conventional carbon steel, stainless steel is steadily growing in popularity [1]. Corrosion resistance is the property most often cited as the reason for its adoption while the high initial material cost acts to limit the number of suitable applications. This situation may, however, be about to alter with the introduction of low nickel (lean duplex) stainless steel [2] at a material cost of around twice that of carbon steel - this could make hitherto prohibitively expensive applications much more cost effective.

This situation of growing popularity has been assisted during the past decade through the production of Design Standards [3-6]. All of these, however, borrow heavily from design rules for carbon steel [7-9] taking little, if any, account of the fundamentally different stressstrain properties of stainless steel. Most important of these for structural behaviour is the rounded uniaxial stress-strain curve, meaning that there is no sharp yield-point and that as the strains increase so material strength continues to rise. Current Design Codes for stainless steel [3-6], therefore, tend to follow rules for cold-formed (or light gauge) steel [8,9] - even though the physical properties of the materials are somewhat different.

Work on the behaviour of stainless steel members, covering local and member buckling [10] has shown that explicit recognition of stainless steel's stress-strain behaviour leads to significant improvements in design capacity. Moreover, concepts such as cross-sectional classification have been shown to be inappropriate [11], leading to the development of more suitable treatments; some of these e.g. the continuous strength method for determining crosssectional strength, have subsequently been shown to be advantageous when dealing with carbon steel [12].

Joints between stainless steel members may generally involve either bolting or welding, with bolted connections typically favoured on site. The authors [13] have previously reviewed all 
the available test data on stainless steel bolted connections. This previous study [13] did, however, focus on net section failure, while the present paper covers arrangements in which bearing failure of the plate elements governs. This is done through the use of a comprehensive and rigorous finite element analysis, suitably validated against test data that has permitted several detailed facets of behaviour, not previously fully understood, to be explained. Of particular significance is the development of a rational and consistent criterion for bearing failure. Use of this leads to simplifications and improvements in the current design rules $[3,4]$.

\section{Failure Criteria for Bolted Joints Operating in Shear}

Bolts operating in shear are a fundamental component of many forms of steelwork connection. For such arrangements, three modes of failure are possible, as illustrated in Fig. 1:

1. Bolts fail in shear.

2. Plates fail in tension at net section.

3. Bolts or plates fail in bearing.

Of these, the first and second are well understood, with clear failure criteria corresponding to fracture in either the bolt shank or the plate respectively. Because the strength of the bolt material in bearing under the tri-axial stress conditions experienced within the hole will almost certainly be substantially greater than that of the surrounding plate, bearing failure of bolts is extremely unlikely, being possible only for combinations of low strength bolts and very high strength plates [14]. Bearing failure of the plates is, however, far more common and somewhat more problematic. Fig. 2 shows the load-deflection relationship for a single bolt in an arrangement for which the proportions are such that neither bolt shear nor net section rupture are critical. The curves omit any possible slip phase and assume that the bolt bears directly against the back of the hole from the start of loading. The results shown are for a carbon steel test [15] and a numerical simulation, performed herein, of the same test, but using austenitic stainless steel material properties. In the absence of a distinct failure due to end tear out (which can be eliminated by ensuring adequate end distances), the curves show no clear maximum - deflections become very large and load continues to rise - significantly so in the case of stainless steel and less so for carbon steel because the form of the material 
stress-strain curve causes the load-deformation relationship to flatten out as deflections increase. The form of the load-deflection relationship in the absence of a clear failure event for carbon steel has led to bearing failure often being defined in terms of a limiting displacement. Sometimes such limits are also associated with a separate limit on allowable deflection under working loads but with the results being presented purely as an ultimate load based criterion. Clearly, for the carbon steel specimen of Fig. 2, selecting the displacement limit as $6 \mathrm{~mm}$ or $12 \mathrm{~mm}$ makes only a few percent difference to the associated 'ultimate load'. However, for stainless steel the shape of the load-deflection relationship is such that changing from a $6 \mathrm{~mm}$ to a $12 \mathrm{~mm}$ displacement limit will lead to about $30 \%$ increase in bearing resistance. Clearly, some form of consistency, preferably allied to an event with clear physical significance, would be preferable. A possible answer is provided herein.

\section{Finite element (FE) models}

\subsection{General}

The finite element analysis software ABAQUS 6.7-1 [16] was used to develop numerical models for austenitic and ferritic stainless steel bolted connections to examine their response under static shear loading. The characteristics and applications of the different families of stainless steels have been previously set out [1]. The configurations of the modelled specimens are presented in Fig. 3. In order to reduce the size of the model and, consequently, the computational cost, only one quarter of the connection was modelled by applying appropriate boundary conditions. The 3D solid (brick) element with full integration - C3D8 which has been shown to be suitable for modelling bolted lap joints in several previous investigations $[17,18]$ was employed in this study to model both the plates and the bolts. Loading was applied by means of uniform displacement-control at the end of the central plate. Fig. 3 illustrates the loading and the boundary conditions applied to the FE models.

The compound Ramberg-Osgood stress-strain model developed by Mirambell and Real [19] and Rasmussen [20] was adopted to represent the non-linear material response of stainless steel; this model was also adopted by Kiymaz [21] in a previous study of stainless steel connections. Numerical analyses of bolted connections are expected to involve large inelastic strains, therefore, nominal stresses and strains were converted to the corresponding true 
values, which take into account the change in geometry under load. Contact between all components that were expected to interact with each other was defined using the surface-tosurface contact feature in ABAQUS. Frictional effects were taken into account by using the classical isotropic Coulomb friction model. Bolts were located centrally into the holes with a uniform clearance of $1.0 \mathrm{~mm}$. Different levels of bolt preload were applied. Loads were carried initially by friction until the occurrence of slippage, after which direct bearing was the primary means of load transfer. A detailed description of the development of these FE models can be found in Reference [13].

\subsection{FE model validation}

Validation of the FE models was made against a series of tests on stainless steel bolted connections performed by Ryan [22]. Load-deformation curves for all 24 tests were compared with those obtained from the numerical models. It is clear from the typical curves shown in Fig. 4 that the predicted load-deformation relationships are in good agreement with the tests. Note that the extension shown is the total deformation of the connection, as illustrated in Fig. 5(a). Some test specimens exhibited a clear failure either by net section rupture or bolt shear, in which cases, the numerical predictions of ultimate load (based on previously described failure criteria [13]) were in good agreement with the test results. Other tests were terminated prior to the attainment of ultimate load - these specimens were said to have failed by bearing owing to excessive deformation. For all tests, the load-deformation curves were consistently accurately replicated. For the tests that exhibited a true failure, a mean FE/test ratio of ultimate loads of 0.99 and a standard deviation of 0.03 were achieved [13]. The deformed shapes of typical test specimens, failing (based on excessive deformation) by bearing (Fig. 5(a)) and net section rupture (Fig. 5(b)), together with the corresponding FE model simulations, are shown in Fig. 5. The validated FE models are used in Section 4 of this paper to highlight various behavioural features of bolted lap connections, while extensive parametric studies are performed in Section 5.

\section{Bearing capacity of bolted lap connections}

In bearing type connections, load is initially transferred by friction until the occurrence of slip, after which the bolt shank and the side of the bolt hole come into direct contact. Bearing 
stresses are developed at the contact surfaces. As the applied load increases, contact stresses increase until bearing failure finally occurs. The bearing resistance of bolted connections has been determined in previous studies either on the basis of a strength or a deformation criterion. These two concepts are discussed in this section.

\subsection{Strength criterion}

When strength is the determining factor, the bearing capacity of a bolted connection is taken as the maximum load attained in the test regardless of the associated deformation. Many researchers [23-26] who conducted experimental studies adopted this criterion to develop bearing design equations even though large deformations were observed at the ultimate load. For instance, Rogers and Hancock [25] developed a bearing design equation for cold-formed carbon steel bolted connections based on the maximum loads from their tests, even though in many specimens a level of deformation as large as $15 \mathrm{~mm}$ was reached. In the abovementioned studies and in Kim's [15] experimental work, the researchers observed that bearing failure i.e. the attainment of a peak on the load-displacement relationship, corresponded with fracture at the edge of the elongated bolt hole at two symmetrical locations oriented at approximately $\theta=45^{\circ}$ and $135^{\circ}$ to the axis of loading; $\theta$ is defined in Fig. 6, which also sets out the configurations considered in the parametric studies described in the next section. These findings appear to be consistent, irrespective of the exact arrangement tested i.e. value of $e_{1} / d_{0}, e_{2} / d_{0}$, bolt size/plate thickness, number and arrangement of bolts etc. As shown in Fig. 7 and discussed further in the next section, for connection geometries where bearing is critical, peak strains may also be observed in the numerical results at these two symmetrical locations $\left(\theta=45^{\circ}\right.$ and $\left.135^{\circ}\right)$ indicating that fracture will initiate at these points.

\subsection{Deformation criterion}

The bearing resistance of a connection according to this second criterion is taken as the applied load measured at a pre-specified acceptable deformation depending upon the application. This limit does not correspond to the maximum load attained in the test and hence, no rupture takes place in the material. The determination of bearing failure loads of bolted shear connections through limiting deformations has been performed by many researchers. However, there has been no consensus about whether to limit the permanent or 
the total elongation, nor on the value to adopt as a suitable deformation limit. Perry [27] investigated carbon steel bolted connections, and recommended that the failure load be the load corresponding to a deformation of $6.35 \mathrm{~mm}$, since beyond this level, the load-deflection curves of typical connections become virtually flat. Perry's definition has been adopted in developing design guidance for carbon steel connections in the AISC Specification [28]. The SCI/Euro Inox [4] design provisions for stainless steel connections were developed on the basis of a $3.0 \mathrm{~mm}$ deformation limit under ultimate conditions. By imposing this limit, it was suggested that the deformation under service loads would be of the order of $1.0 \mathrm{~mm}$. Eurocode 3 Part 1.4 [3] adopted the same design provisions. The deformation-based definition of bearing failure has led to an inconsistent approach with - as Fig. 2 has already illustrated failure load levels being dependent on an, often, arbitrary selection of a limiting deformation.

\subsection{Failure modes and connection geometry}

In order to distinguish between end tear-out failure and bearing failure from the FE models, a failure criterion that depends on the deformation of the connection has been devised. In the FE models five reference points A, B, C, D, E and F were assigned to the plate as shown in Fig. 8. The overall deformation of a connection is often considered as the elongation of the plate parallel to the direction of the load between points $\mathrm{C}$ and E. Four components of deformation contribute to the plate elongation to a different degree depending on the precise arrangement. The first is the relative horizontal displacement between points A and B. Since this deformation shows approximately the protrusion of the bolt from the plate material, it will be called 'Bolt protrusion'. The second component is the shortening of the plate material in front of the bolt, which is measured by the relative horizontal displacement between points B and C. Because this part measures the amount of the bolt embedding into the plate material, it will be called 'Bolt embedding'. The third component of deformation is the elongation in the net section that occurs as a result of the high stresses over the net section. This elongation is approximately twice the relative horizontal displacement between points D and F. The fourth component that contributes to the overall elongation is the elongation in the gross section and this is measured as a relative displacement between points D and E. The elongation in the gross section of the plate is very small relative to other sources of deformation as shown in Figs. 9 to 11 . 
By examining the relative contributions of these components of deformation, three failure modes can be identified. When the 'Bolt protrusion' constitutes the majority of the deformation, as shown in Fig. 9, the connection has failed by end tear-out. This mode takes place in connections with small end distances as can be seen in Fig. 12. In connections with relatively small edge distance $e_{2}$, the deformation is essentially due to net section elongation as shown in Fig. 10 - net section fracture is the mode of failure in this case (see Fig. 13). When the deformation of the plate is mainly due to the 'Bolt embedding' as shown in Fig. 11, the failure mode is bearing (see Fig. 14). Note that this criterion is used solely to distinguish between end-tear out and bearing failure, while the failure load is determined by employing the strain-based criterion which has been discussed in the next section (Fig. 7).

\section{Parametric studies}

\subsection{General}

In order to investigate the bearing behaviour of stainless steel bolted connections so as to assess, and where necessary modify, the current bearing design guidance, the validated FE models have been employed to conduct parametric studies. The results of these studies are used in Section 6 of this paper as the basis for proposing design equations for connections between both thick and thin plates. In order to investigate the effects of the degree of roundedness of the stress-strain curve and the level of stain hardening of the material on the bearing behaviour, two types of stainless steels were studied - austenitic and ferritic. Specifically, austenitic grade 1.4306 and the ferritic grade 1.4016 were investigated, with these grades considered to be representative of their respective families. The material properties of these stainless steels are shown in Table 1. The investigated parameters include the end distance $e_{1}$, the edge distance $e_{2}$ and the thickness of the plate $t$, with a constant bolt diameter of $20 \mathrm{~mm}$.

Two additional phenomena are associated with the bearing behaviour of thin sheet connections as compared to thick sheet connections: curling and pulling into line. Curling is the out-of-plane deformation of the connected sheet in front of the end bolt. This deformation, which occurs in both sheets in single shear connections and in the outer sheets of double shear connections, is effectively buckling of the plate when it is subjected to compressive stresses 
[29]. The part of the plate in front of the end bolt can be regarded as a strut that is fixed at one end by means of the bolt head or nut and is free at the other end. Pulling into line only takes place in single shear connections to permit the applied tensile loads, which are initially acting at an eccentricity to one another and inducing bending of the plate, to act along the same line (see Fig. 18(b)).

Eurocode 3 Part 1.3 [8] provides design expressions for bolted connections between thin plates with thicknesses of $4.0 \mathrm{~mm}$ or less. This $4.0 \mathrm{~mm}$ limit has also been adopted in the present study to mark the transition between 'thick' and 'thin' material; hence, $8.0 \mathrm{~mm}$ and $10.0 \mathrm{~mm}$ thick plates were investigated to represent thick plate connections, while plates with thicknesses of $1.0 \mathrm{~mm}$ and $2.0 \mathrm{~mm}$ were used to investigate thin plate connections.

\subsection{Connections between thick plates}

For thick plates, lap connections with bolts in double shear and plate thicknesses of $8.0 \mathrm{~mm}$ and $10.0 \mathrm{~mm}$ were investigated. The arrangement of the FE models is shown in Fig. 6(a). The end distance ratio $e_{1} / d_{0}$ was varied from 0.8 to 4.0 ; for the edge distance ratio $e_{2} / d_{0}$, four values $(1.5,2.0,3.0$ and 4.0) were used.

A typical distribution of plastic strain in the plate in front of the bolt obtained from the FE model is presented in Fig. 7(a). It shows that the strains are very high at two symmetrical locations at about $\theta=45^{\circ}$ and $135^{\circ}$. This strain distribution accords with the observations from the experimental studies discussed in Section 4 and confirms that bearing fracture initiates at these two locations of peak strain. This conclusion is adopted in the present study to define the bearing capacity of a connection when using the strength criterion: when the peak plastic strain in the plate material in front of the bolt reaches the localized fracture strain of the material (Salih et al. [13]), fracture occurs and the maximum load is said to have been reached.

The load-deformation plot given in Fig. 15(a) shows the stiffness at three stages of loading of typical stainless steel connections which failed by bearing. The stiffness at the point of bearing fracture is almost equal to the stiffness at $6.35 \mathrm{~mm}$ deformation and is about $50 \%$ of the stiffness at $3.0 \mathrm{~mm}$ deformation. For a corresponding connection failing by net section 
rupture, Fig. 16 shows that the stiffness at fracture is about $25 \%$ of that at $6.35 \mathrm{~mm}$ deformation and about $12 \%$ of that at $3.0 \mathrm{~mm}$ deformation. It is clear that for connections failing by bearing the loss of stiffness at bearing fracture is relatively modest compared to the loss of stiffness at net section fracture in connections failing by net section rupture. Thus, it may be concluded that defining bearing failure on the basis of deformation limits $(3.0 \mathrm{~mm}$ or $6.35 \mathrm{~mm}$ ), underestimates the true bearing resistance of stainless steel connections. Furthermore, for consistency with net section failure, in which the ultimate load is taken as the load causing fracture, it is proposed that the load at bearing fracture can be considered as the bearing ultimate load. Note that connection deformation is measured as the elongation between points A and B, shown in Fig. 6.

\subsection{Connections between thin sheets}

The bearing behaviour of bolted connections composed of thin sheets was thoroughly examined by considering three scenarios. The first scenario addresses the case of double shear connections in which the inner sheet is critical. In this case, due to the restraint provided by the outer sheets, curling will be prevented. The second scenario again considers double shear connections, but those in which the outer sheets are critical and curling is expected. The third scenario covers bolted connections in single shear where both curling and pulling into line take place.

\subsubsection{Inner sheets in double shear connections}

A set of FE models for the double shear configuration shown in Fig. 6(a) was developed with plate thicknesses of 1.0 and $2.0 \mathrm{~mm}$. The end distance ratio $\mathrm{e}_{1} / \mathrm{d}_{0}$ was varied from 0.8 to 4.0 ; for the edge distance ratio $e_{2} / d_{0}$, three values $(1.5,2.0$ and 3.0$)$ were used. The bearing response in this situation is found to be similar to that for thick plate connections. The stiffness for a connection with thin plates at different load levels shown in Fig. 15(b) exhibits a rising load-deformation behaviour. Fig. 7(b) shows that the distribution of strains in front of the bolt has the same peak values at about $\theta=45^{\circ}$ and $135^{\circ}$. The overall response of the inner sheets in double shear connections may therefore be said to be insensitive to the material thickness. 


\subsubsection{Single shear connections and outer sheets in double shear connections}

To investigate the effects of curling and pulling into line on the bearing behaviour of stainless steel bolted connections, the load-deformation curves from three configurations of FE model with sheet thickness $\mathrm{t}=2.0 \mathrm{~mm}$ were compared. These models can be described as follows:

- Model I: double shear connection as shown in Fig. 6(b) where out-of-plane deformation (curling) of the outer sheets is prevented by applying appropriate boundary conditions.

- Model II: double shear connection as shown in Fig. 6(b) where out-of-plane deformation (curling) of the outer sheets is permitted.

- Model III: single shear connection as shown in Fig. 6(c) with no restraint against out-of plane deformation (curling).

Fig. 17 shows a comparison between the results obtained for the above mentioned connections, while Fig. 18 shows the deformed shapes for Models II and III. It can be concluded that while curling, which occurs in both single and double shear connections, significantly affects the load carrying capacity of connections, pulling into line, which takes place in single shear connections only, does not affect bearing behaviour. Thus, Models II and III are effectively equivalent. This behaviour has been previously observed. For instance, the tensile behaviour of lap connections between thin sheets was studied experimentally [30] and then numerical models were employed to simulate theses specimens [31]. The test setup consisted of single bolted connections between thin sheets $(1.5 \mathrm{~mm}$ or $3.0 \mathrm{~mm})$ which were considered to be the test specimens, and thick plates $(6.0 \mathrm{~mm})$ in which no significant deformation occurred. When these tests were replicated using FE models [31], only the thinner sheet and bolts were modelled. This indicates that only the curling phenomenon was thought to affect the behaviour of bolted connections between thin sheets. Moreover, the AISI Specification [9] provides bearing design equations for bolted connections between thin carbon steel sheets for two situations; the first covering the inner sheet in double shear 
connections, and the second covering single shear connections and the outer sheets in double shear connections.

The FE models of the single shear connections between thin sheets were frequently unstable preventing full solutions from being achieved. However, it was shown earlier that the behaviour of the outer sheet in double shear connections can also represent the behaviour in single shear; the arrangement in Fig. 6(b) was therefore adopted to conduct parametric studies to represent both connection types. The end distance ratio varied from 0.8 to 4.0 with three values of the edge distance ratio $e_{2} / \mathrm{d}_{0}(1.5,2.0$ and 3.0). Despite the occurrence of curling, the strain distribution in the plate in front of the bolt as shown in Fig. 7(c) remains consistent with that previously observed in Sections 5.2 and 5.3.1, with peak strains arising at two symmetrical points at approximately $\theta=45^{\circ}$ and $135^{\circ}$. Thus, the originally proposed failure criterion remains valid.

\section{Current design provisions}

\subsection{General}

All existing carbon steel and stainless steel design standards consider end tear-out and bearing failure as one limit state by providing a design equation that relates end tear-out capacity to the end distance, and then setting an upper limit for this equation. The general form of bearing capacity design expressions is given by:

$$
\mathrm{N}_{\mathrm{b}}=\alpha \operatorname{tdf}_{\mathrm{u}} \leq \operatorname{Ctdf}_{\mathrm{u}}
$$

where $\alpha$ is the bearing coefficient which is linearly related to the end distance $\mathrm{e}_{1}$ and $\mathrm{C}$ is the upper constant value of the coefficient $\alpha$ for end distances $e_{1}$ equal to or greater than a limiting value.

\subsection{Eurocode 3 and SCI/Euro Inox Design Manual}

The design bearing resistance of carbon steel connections in Eurocode 3 Part 1.8 [7] is given by: 


$$
\mathrm{N}_{\mathrm{b}, \mathrm{EC} 3}=\frac{\mathrm{k}_{1} \alpha_{\mathrm{b}} \mathrm{tdf}_{\mathrm{u}}}{\gamma_{\mathrm{M} 2}}
$$

where $\alpha_{b}$ is the smallest of $\alpha_{d}, f_{u b} / f_{u}$ (where $f_{u}$ and $f_{u b}$ are the ultimate tensile strengths of the plate and bolt material respectively) or $1.0, \mathrm{t}$ is the plate thickness, $\mathrm{d}$ is the nominal bolt diameter and $\gamma_{\mathrm{M} 2}$ is a partial safety factor with a recommended value of 1.25 . In the direction of load transfer, $\alpha_{d}=e_{1} / 3 d_{0}$ for end bolts and $\left(p_{1} / 3 d_{0}-1 / 4\right)$ for inner bolts, where $d_{0}$ is the bolt hole diameter, $\mathrm{e}_{1}$ is the end distance and $\mathrm{p}_{1}$ is the spacing between bolts in the direction of loading. In the direction perpendicular to load transfer, $\mathrm{k}_{1}$ is the smaller of $\left(2.8 \mathrm{e}_{2} / \mathrm{d}_{0}-1.7\right)$ or 2.5 for edge bolts and $\left(1.4 \mathrm{p}_{2} / \mathrm{d}_{0}-1.7\right)$ or 2.5 for inner bolts where $\mathrm{e}_{2}$ is the edge distance.

The SCI/Euro Inox Design Manual for Structural Stainless Steel [4] and Eurocode 3 Part 1.4 [3] adopt Equation 2 for austenitic and duplex stainless steel connections with a minor modification: a reduced ultimate strength of the plate material $f_{u, r e d}$ obtained from Equation 3 is used in place of $f_{u}$ in Equation 2. This modification was proposed [4] to limit bearing deformations at the ultimate and service loads to acceptable levels, while maintaining the format of the resistance equation and the bearing coefficients for carbon steel. The two standards apply these provisions for connections between both thick hot-rolled plates and thin cold-formed sheets.

$$
\mathrm{f}_{\mathrm{u}, \mathrm{red}}=0.5 \mathrm{f}_{\mathrm{y}}+0.6 \mathrm{f}_{\mathrm{u}} \leq \mathrm{f}_{\mathrm{u}}
$$

\subsection{American and Australian Standards}

The ASCE [5] and AS/NZS [6] Standards provide design rules for bolted connections between thin cold-formed stainless steel elements but do not cover thick hot-rolled material. These Standards adopt the design provisions for bearing set out in the AISI Standard [9] for cold-formed carbon steel bolted connections with a minor modification which is that the upper limit of the bearing capacity (given in Equations 4 and 5) is marginally reduced. The bearing resistance of cold-formed stainless steel connections, which have been arranged in the format of Eurocode 3 for comparison purposes, is given by Equations 4 and 5 . 
for single shear connections: $\quad \mathrm{N}_{\mathrm{b}, \mathrm{ASCE}}=\phi_{\mathrm{end}}\left(\frac{\mathrm{e}_{1}}{\mathrm{~d}}\right) \mathrm{tdf}_{\mathrm{u}} \leq \phi_{\text {bear }}\left(2.0 \mathrm{tdf}_{\mathrm{u}}\right)$

for double shear connections: $\quad \mathrm{N}_{\mathrm{b}, \mathrm{ASCE}}=\phi_{\mathrm{end}}\left(\frac{\mathrm{e}_{1}}{\mathrm{~d}}\right) \mathrm{tdf}_{\mathrm{u}} \leq \phi_{\mathrm{bear}}\left(2.75 \mathrm{tdf}_{\mathrm{u}}\right)$

where $\phi_{\text {end }}$ and $\phi_{\text {bear }}$ are the end tear-out and bearing resistance factors of 0.7 and 0.65 respectively.

\section{Proposed design rules}

In this section, the results obtained from the parametric studies are used to propose bearing design equations for hot-rolled and cold-formed stainless steel bolted connections. Since the bearing response of austenitic and ferritic stainless steels was found to be similar as discussed in Section 5, these steels will be treated similarly in design. In order to exploit the high ductility and strain hardening characteristics of stainless steel, the concept in the AISC Standard [28] for bearing design will be adopted. Two bearing design equations will be proposed according to whether or not a deformation limit under service loads is required. The first bearing design equation is for bolted connections where the deformation under service loads is not a design consideration. This equation will be developed by adopting the strength criterion to define the ultimate bearing capacity, as controlled by fracture. The second equation is for connections where the deformation under service loads is a design consideration, and therefore the equation will be developed by considering the deformation criterion to define the service load and consequently the corresponding ultimate bearing capacity. It should be noted that two essential features were considered when suggesting the design equations. Firstly, the format of the equation is to be similar to that of Equation 1 and secondly, the ultimate tensile strength $f_{u}$ is to be used instead of a combination between the yield strength $f_{y}$ and ultimate strength $f_{u}$ which is adopted in EN 1993-1-4 [3] and the SCI/Euro Inox Design Manual [4].

7.1 Bearing capacity when deformation under service loads is not a design consideration 
For this first scenario, the ultimate bearing capacity is taken as the load that corresponds to bearing fracture $\mathrm{N}_{\mathrm{b} \text {,frac }}$, as discussed in Section 5 . The corresponding bearing coefficients $\beta_{\mathrm{b} \text {,frac }}$ defined by Equation 6, obtained from the parametric studies are plotted against the edge distance ratio $e_{1} / d_{0}$ in Figs. 19, 21 and $23-\sigma_{b \text {,frac }}$ is the nominal bearing stress at fracture.

$$
\beta_{\mathrm{b}, \text { frac }}=\frac{\mathrm{N}_{\mathrm{b}, \text { frac }}}{\mathrm{tdf}_{\mathrm{u}}}=\frac{\sigma_{\mathrm{b}, \text { frac }}}{\mathrm{f}_{\mathrm{u}}}
$$

\subsection{Bearing capacity when deformation under service loads is a design consideration}

In this second scenario, the ultimate bearing capacity of the bolted connection is defined such that the deformation at the serviceability limit state is kept within an acceptable limit. Examining the load-deformation curves for all FE models, it was found that at $1.0 \mathrm{~mm}$ deformation the connections remain essentially elastic. Therefore, a service load corresponding to $1.0 \mathrm{~mm}$ deformation was adopted, and the corresponding ultimate bearing capacity $\mathrm{N}_{\mathrm{b} \text {,def }}$ (here controlled by deformation) was then obtained by assuming an average ratio of ultimate to service loads of 1.45. Figs. 20, 22 and 24 show the resulting bearing coefficient $\beta_{\mathrm{b} \text {,def }}$ from Equation 7; $\sigma_{\mathrm{b} \text {,def }}$ is the corresponding nominal bearing stress.

$$
\beta_{\mathrm{b}, \mathrm{def}}=\frac{\mathrm{N}_{\mathrm{b}, \mathrm{def}}}{\mathrm{tdf}_{\mathrm{u}}}=\frac{\sigma_{\mathrm{b}, \mathrm{def}}}{\mathrm{f}_{\mathrm{u}}}
$$

For this situation, the proposed design equations will ensure that the deformation at serviceability will be acceptable; there is, therefore, no need to conduct a separate check.

\subsection{Connections composed of thick plates}

\subsubsection{Deformation under service loads is not a design consideration}

Fig. 19 shows the nominal bearing stress at fracture $\beta_{\mathrm{b} \text {,frac }}$ for thick plate connections obtained from the parametric studies. It can be seen that the bearing stress factor is greater than $\alpha_{1}$ as defined by Equation 8 . 


$$
\alpha_{1}= \begin{cases}2.5\left(\frac{\mathrm{e}_{1}}{3 \mathrm{~d}_{0}}\right) \leq 2.5 & \text { for } \mathrm{e}_{2} / \mathrm{d}_{0}>1.5 \\ 2.5\left(\frac{\mathrm{e}_{1}}{3 \mathrm{~d}_{0}}\right) \leq 2.0 & \text { for } \mathrm{e}_{2} / \mathrm{d}_{0} \leq 1.5\end{cases}
$$

Thus, the proposed bearing design equation for connections where deformation is not a consideration is given by Equation 9.

$$
\mathrm{N}_{\mathrm{b}, \text { frac,prop }}=\alpha_{1} \mathrm{tdf}_{\mathrm{u}}
$$

\subsubsection{Deformation under service loads is a design consideration}

The factor $\alpha_{2}$ given by Equation 10 may be seen to provide a lower bound to the finite element data plotted in Fig. 20. Thus, Equation 11, with $\alpha_{2}$ from Equation 10, is proposed for the determination of ultimate bearing capacity when limiting deformation is a design consideration.

$$
\begin{gathered}
\alpha_{2}=1.25\left(\frac{\mathrm{e}_{1}}{2 \mathrm{~d}_{0}}\right) \leq 1.25 \\
\mathrm{~N}_{\mathrm{b}, \text { def }, \text { prop }}=\alpha_{2} \mathrm{tdf}_{\mathrm{u}}
\end{gathered}
$$

\subsection{Connections composed of thin plates}

\subsubsection{Inner sheets in double shear connections}

\subsubsection{Deformation under service loads is not a design consideration}

It can be seen from Fig. 21 that the bearing coefficient $\beta_{\mathrm{b} \text {,frac }}$ (based on fracture) obtained from the FE models is greater than $\alpha_{1}$, defined by Equation 8 . Therefore, the ultimate capacity for this type of connection, when deformation is not a design consideration, may be obtained from Equation 9.

7.4.1.2 Deformation under service loads is a design consideration 
The factor $\alpha_{2}$ defined by Equation 10 may be seen to provide a lower bound to the bearing coefficient (based on limiting deformation) $\beta_{\mathrm{b}, \mathrm{def}}$ plotted in Fig. 22. The ultimate bearing capacity for this design scenario may therefore be taken from Equation 11.

\subsubsection{Single shear connections and outer sheets in double shear connections}

\subsubsection{Deformation under service loads is not a design consideration}

The bearing coefficients $\beta_{\mathrm{b} \text {,frac }}$ based on fracture for single shear connections and the outer sheets of double shear connections (i.e. where plate curling may be expected) are plotted in Fig. 23. The factor $\alpha_{3}$ defined by Equation 12 may be seen to provide a lower bound to these bearing coefficients.

$$
\alpha_{3}=1.6\left(\frac{\mathrm{e}_{1}}{2 \mathrm{~d}_{0}}\right) \leq 1.6
$$

Thus, the proposed bearing design equation for this scenario is given by Equation 13 .

$$
\mathrm{N}_{\mathrm{b}, \text { frac,prop,c }}=\alpha_{3} \mathrm{tdf}_{\mathrm{u}}
$$

\subsubsection{Deformation under service loads is a design consideration}

The bearing coefficients $\beta_{\mathrm{b} \text {,def }}$ for the same categories of connections, but for limiting deformations, are shown in Fig. 24. For this figure, it may be seen that the factor $\alpha_{2}$ given by Equation 10 provides a lower bound to these data. It is therefore proposed that the ultimate bearing capacity be given by Equation 11 . The proposed design equations are summarised in Table 2.

\section{Conclusions}

The bearing behaviour of stainless steel connections has been investigated herein by means of FE parametric studies. The fundamental difference in the response of stainless steel and 
carbon steel connections is that, while the load-deformation curve for carbon steel connections flattens off after the initiation and spreading of yielding, for stainless steel connections this curve continues to rise significantly owing to strain hardening. For this reason, greater clarity in defining bearing capacity than has previously been used when considering carbon steel connections was necessary. Different failure definitions have therefore been devised for stainless steel connections, and bearing design equations for both thick and thin material that cover two cases - one restricting and one ignoring serviceability deformations - have been

proposed. These equations define the bearing capacity in terms of the material ultimate strength $f_{u}$ instead of the so-called reduced ultimate strength $f_{u, \text { red }}$, and therefore, are consistent with the provisions for carbon steel connections. The proposed equations, which are based on all available test data and the numerical results generated herein, provide a modest enhancement in capacity compared to the current EC3 approach as well as being simpler to use.

\section{Acknowledgements}

The authors are grateful to the University of Khartoum (Sudan) and the Prof. Shawki Saad Scholarship for sponsoring this research.

\section{References}

[1] Gardner, L. (2005). The use of stainless steel in structures. Progress in Structural Engineering and Materials. 7(2), 45-55.

[2] Theofanous, M. and Gardner, L. (2009). Testing and numerical modelling of lean duplex stainless steel hollow section columns. Engineering Structures. 31(12), 3047-3058.

[3] EN 1993-1-4 (2006). Eurocode 3: Design of steel structures - Part 1.4: General rules Supplementary rules for stainless steel. CEN.

[4] SCI/Euro Inox (2006). Design Manual for Structural Stainless Steel. Third Edition. The Steel Construction Institute and Euro Inox, Building series, Volume 3. 
[5] ASCE (2002). Specification for the design of cold-formed stainless steel structural members, SEI/ASCE 8-02. American Society of Civil Engineers. New York.

[6] Aust/NZS (2001). Cold-formed stainless steel structures. Australian Standard/New Zealand Standard AS/NZS 4673. Sydney, Australia.

[7] EN 1993-1-8 (2005). Eurocode 3: Design of steel structures - Part 1.8: Design of Joints. CEN.

[8] EN 1993-1-3 (2006). Eurocode 3: Design of steel structures - Part 1.3: General rules Supplementary rules for cold-formed members and sheeting. CEN.

[9] AISI (2007). Specification for the design of cold-formed steel structural members. American Iron and Steel Institute, Washington, DC, USA.

[10] Ashraf, M., Gardner, L. and Nethercot, D.A. (2008). Structural stainless steel design: resistance based on deformation capacity. Journal of Structural Engineering, ASCE, 134(3), 404-411.

[11] Ashraf, M., Gardner, L. and Nethercot, D. A. (2006). Compression Strength of Stainless Steel Cross-Sections. Journal of Constructional Steel Research. 62(1-2), 105-115.

[12] Gardner, L. (2008). The Continuous Strength Method. Proceedings of the Institution of Civil Engineers - Structures and Buildings. 161(3), 127-133.

[13] Salih, E. L., Gardner, L. and Nethercot, D. A. (2010). Numerical investigation of net section failure in stainless steel bolted connections. Journal of Constructional Steel Research. 66(12), 1455-1466.

[14] Owens, G. and Cheal, B. (1989). Structural steelwork connections. Butterworth \& Co.

[15] Kim, H. J. (1996). The effect of end distance on the bearing strength of bolted connections. M.Sc dissertation. University of Texas at Austin, USA. 
[16] Hibbitt, Karlsson \& Sorensen, Inc (2007). ABAQUS/Standard User's Manual. Version 6.7-1. Pawtucket, USA.

[17] Chung, K. F. and Ip, K. H. (2000). Finite element modelling of bolted connections between cold-formed steel strips and hot rolled steel plates under static shear loading. Engineering Structures. 22(10), 1271-1284.

[18] Ju, S. H., Fan, C. Y. and Wu, G. H. (2004). Three-dimensional finite elements of steel bolted connections. Engineering Structures. 26(3), 403-413.

[19] Mirambell, E. and Real, E. (2000). On the calculation of deflections in structural stainless steel beams: an experimental and numerical investigation. Journal of Constructional Steel Research. 54(1), 109-133.

[20] Rasmussen, K. J. R. (2003). Full-range stress-strain curves for stainless steel alloys. Journal of Constructional Steel Research. 59(1), 47-61.

[21] Kiymaz, G. (2009). Investigations on the bearing strength of stainless steel bolted plates under in-plane tension. Steel and Composite Structures. 9(2), 173-189.

[22] Ryan, I. (1999). Development of the use of stainless steel in construction WP 4.2. ECSC Project No.7210-SA/327.

[23] Winter, G. (1956). Tests on bolted connections in light gage steel. Journal of Structural Engineering, ASCE. 82(2), 1-25.

[24] Errera, S. J., Popowich, D. W., and Winter, G. (1974). Bolted and welded stainless steel connections. Journal of Structural Engineering, ASCE. 100(6), 2549-2567.

[25] Rogers, C. A., and Hancock, G. J. (1998). New bolted connection design formulae for G550 and G300 sheet steels less than 1.0 mm thick. Research Report No. R769. Department of Civil Engineering, University of Sydney. Australia. 
[26] Puthli, R., and Flischer, O. (2001). Investigation on bolted connections for high strength steel members. Journal of Constructional Steel Research. 57(3), pp. 313-326.

[27] Perry, W. C. (1981). The bearing strength of bolted connections. M.Sc dissertation. University of Texas at Austin, USA.

[28] AISC (2005). Steel Construction Manual. American Institute of Steel Construction. Chicago, US.

[29] Kim, T. S., Kuwamura, H., and Cho, T. J. (2008). A parametric study on ultimate strength of single shear bolted connections with curling. Thin-Walled Structures. 46(1), 38-53.

[30] Kuwamura, H. and Isozaki, A. (2001). Ultimate behaviour of fastener connections of thin stainless steel plates. Journal of steel construction Engineering. 556, 159-166. (in Japanese).

[31] Kim, T. S. and Kuwamura, H. (2007). Finite element modeling of bolted connections in thin-walled stainless steel plates under static shear. Thin-Walled Structures. 45(4), 407-421. 
Table 1: Material properties of stainless steel for the parametric studies

\begin{tabular}{lcccc}
\hline Steel & $\begin{array}{c}\mathrm{f}_{0.2} \\
\left(\mathrm{~N} / \mathrm{mm}^{2}\right)\end{array}$ & $\begin{array}{c}\mathrm{f}_{\mathrm{u}} \\
\left(\mathrm{N} / \mathrm{mm}^{2}\right)\end{array}$ & $\begin{array}{c}\text { Elongation at } \\
\text { fracture }(\%)\end{array}$ & $\mathrm{f}_{\mathrm{u}} / \mathrm{f}_{\mathrm{y}}$ \\
\hline Austenitic grade 1.4306 & 288 & 581 & 62 & 2.02 \\
Ferritic grade 1.4016 & 262 & 522 & 51 & 1.99 \\
\hline
\end{tabular}


Table 2: Summary of the proposed bearing design equations

\begin{tabular}{|c|c|c|c|}
\hline & \multirow[b]{2}{*}{ Connections composed of thick plates } & \multicolumn{2}{|c|}{ Connections composed of thin plates } \\
\hline & & Inner sheets in double shear connections & $\begin{array}{l}\text { Single shear connections and outer } \\
\text { sheets in double shear connections }\end{array}$ \\
\hline $\begin{array}{l}\text { Deformation under } \\
\text { service loads is not a } \\
\text { design consideration }\end{array}$ & $\begin{array}{l}\mathrm{N}_{\mathrm{b}, \text { frac, prop }}=\alpha_{1} \mathrm{tdf}_{\mathrm{u}} \\
\text { where: } \\
\alpha_{1}= \begin{cases}2.5\left(\frac{\mathrm{e}_{1}}{3 \mathrm{~d}_{0}}\right) \leq 2.5 & \text { for } \mathrm{e}_{2} / \mathrm{d}_{0}>1.5 \\
2.5\left(\frac{\mathrm{e}_{1}}{3 \mathrm{~d}_{0}}\right) \leq 2.0 & \text { for } \mathrm{e}_{2} / \mathrm{d}_{0} \leq 1.5\end{cases} \end{array}$ & $\begin{array}{l}\mathrm{N}_{\mathrm{b}, \text { frac, prop }}=\alpha_{1} \mathrm{tdf}_{\mathrm{u}} \\
\text { where: } \\
\alpha_{1}=\left\{\begin{array}{l}2.5\left(\frac{\mathrm{e}_{1}}{3 \mathrm{~d}_{0}}\right) \leq 2.5 \quad \text { for } \mathrm{e}_{2} / \mathrm{d}_{0}>1.5 \\
2.5\left(\frac{\mathrm{e}_{1}}{3 \mathrm{~d}_{0}}\right) \leq 2.0 \quad \text { for } \mathrm{e}_{2} / \mathrm{d}_{0} \leq 1.5\end{array}\right.\end{array}$ & $\begin{array}{l}\mathrm{N}_{\mathrm{b}, \text { frac,prop, } \mathrm{c}}=\alpha_{3} \mathrm{tdf}_{\mathrm{u}} \\
\text { where: } \\
\alpha_{3}=1.6\left(\frac{\mathrm{e}_{1}}{2 \mathrm{~d}_{0}}\right) \leq 1.6\end{array}$ \\
\hline $\begin{array}{l}\text { Deformation under } \\
\text { service loads is a } \\
\text { design consideration }\end{array}$ & $\begin{array}{l}\mathrm{N}_{\mathrm{b}, \text { def, prop }}=\alpha_{2} \mathrm{tdf}_{\mathrm{u}} \\
\text { where: } \\
\alpha_{2}=1.25\left(\frac{\mathrm{e}_{1}}{2 \mathrm{~d}_{0}}\right) \leq 1.25\end{array}$ & $\begin{array}{c}\mathrm{N}_{\mathrm{b}, \text { def }, \text { prop }}=\alpha_{2} \mathrm{tdf}_{\mathrm{u}} \\
\alpha_{2}=1.25\left(\frac{\mathrm{e}_{1}}{2 \mathrm{~d}_{0}}\right) \leq 1.25\end{array}$ & $\begin{array}{l}\mathrm{N}_{\mathrm{b}, \mathrm{def} \text {, prop }}=\alpha_{2} \mathrm{tdf}_{\mathrm{u}} \\
\text { where: } \\
\alpha_{2}=1.25\left(\frac{\mathrm{e}_{1}}{2 \mathrm{~d}_{0}}\right) \leq 1.25\end{array}$ \\
\hline
\end{tabular}


(a) Bolt shear failure
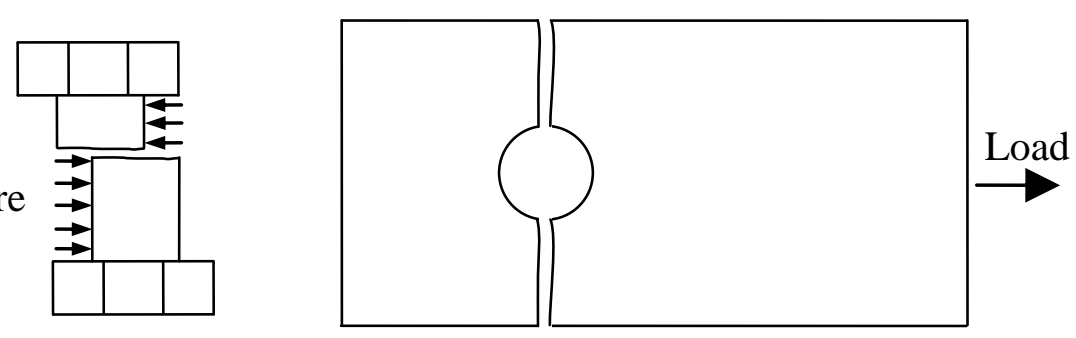

(b) Net section failure

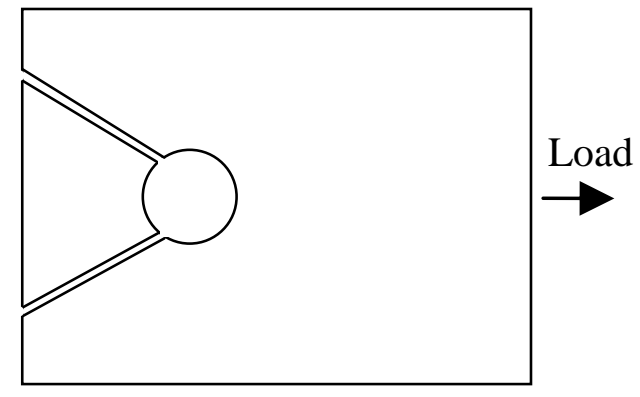

(c) Bearing failure

Fig. 1: Schematic representation of failure modes of bearing-type connections 


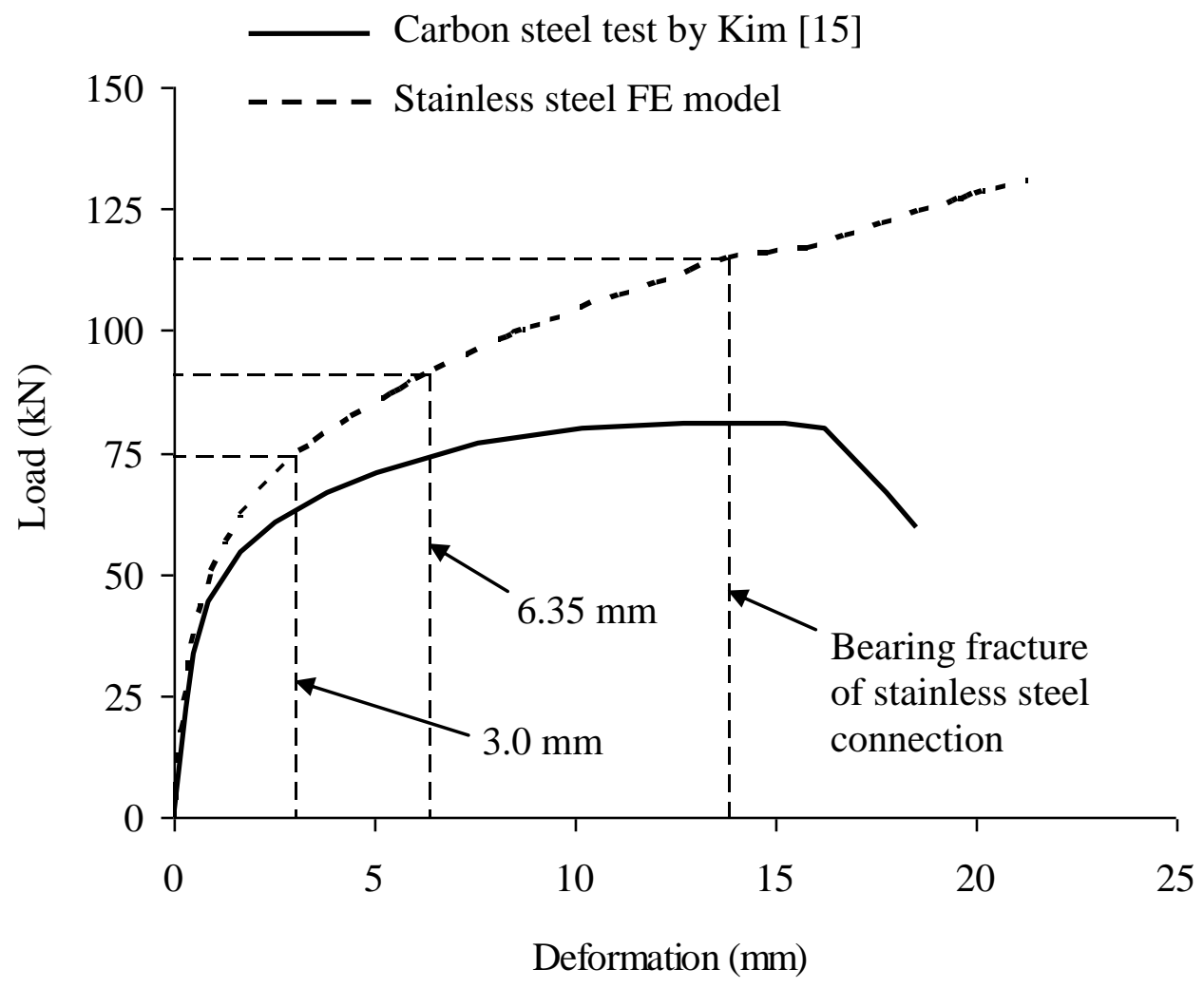

Fig. 2: Comparison between carbon steel and austenitic stainless steel connection behaviour 

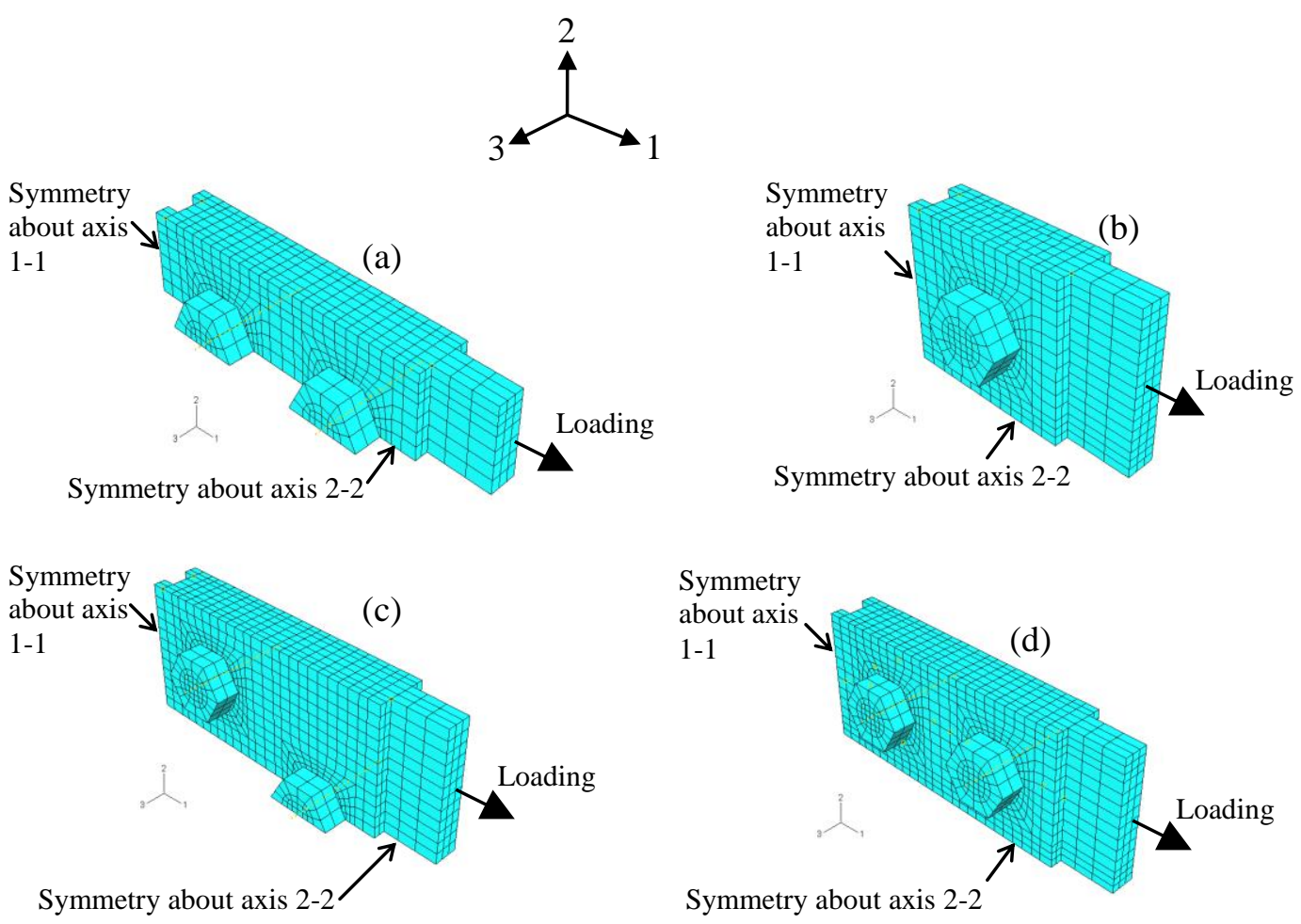

Fig. 3: FE models for bolted connections tested by Ryan [21] 


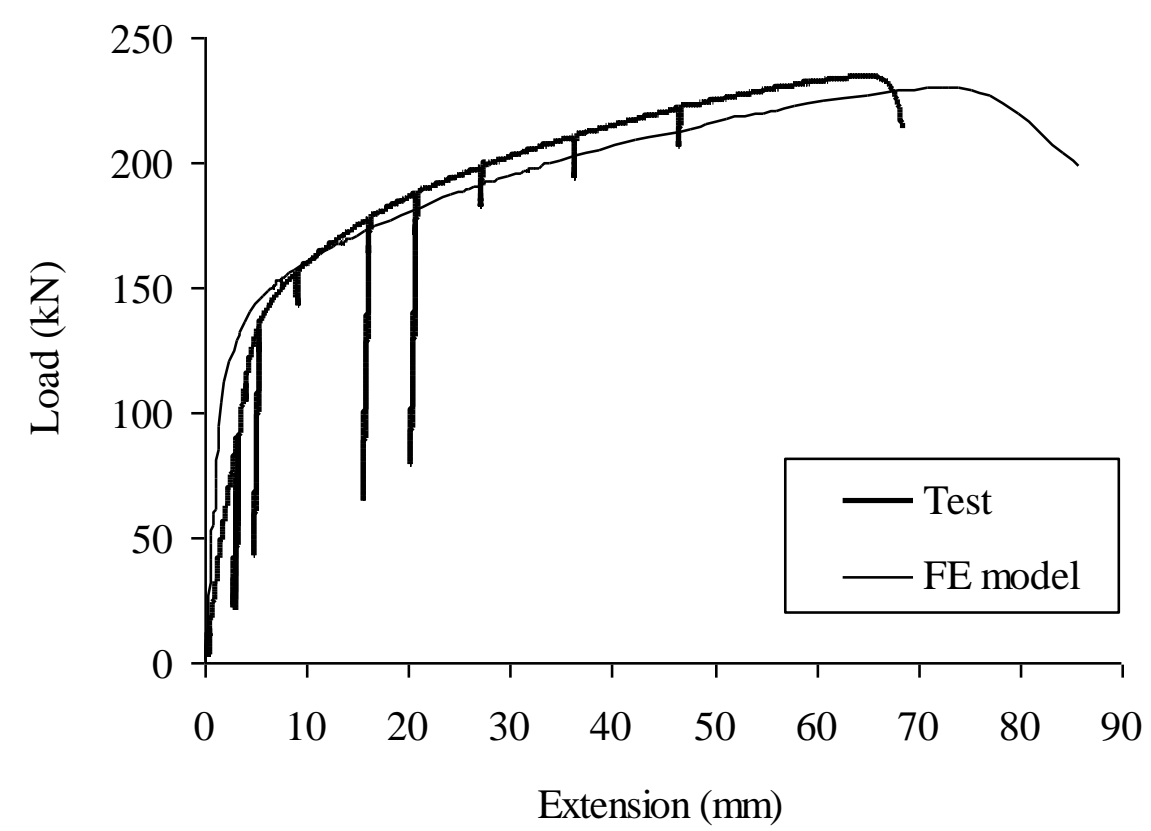

(a) Typical austenitic stainless steel connection with two bolts in one row (see Fig. 3(a))

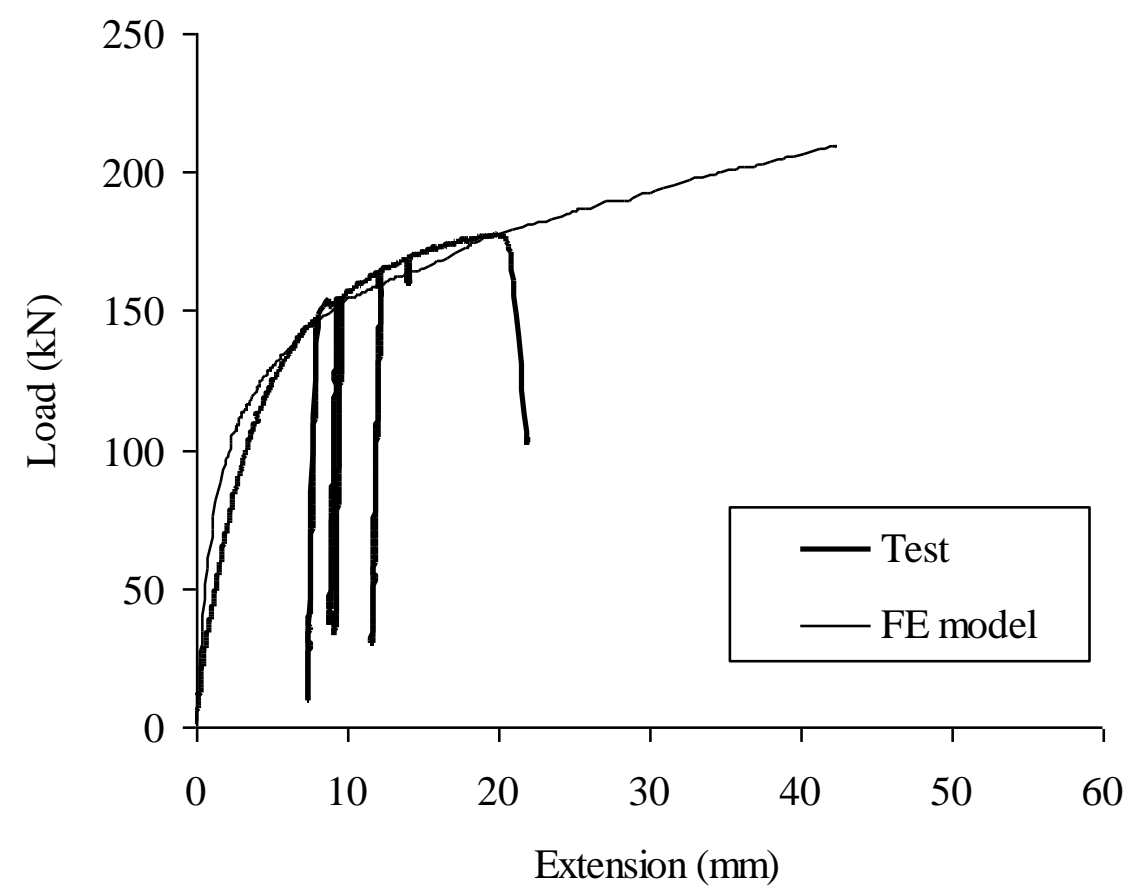

(b) Typical ferritic stainless steel connection with two bolts in two rows (see Fig. 3(b))

Fig. 4: Typical load-deformation curves from tests and numerical models 

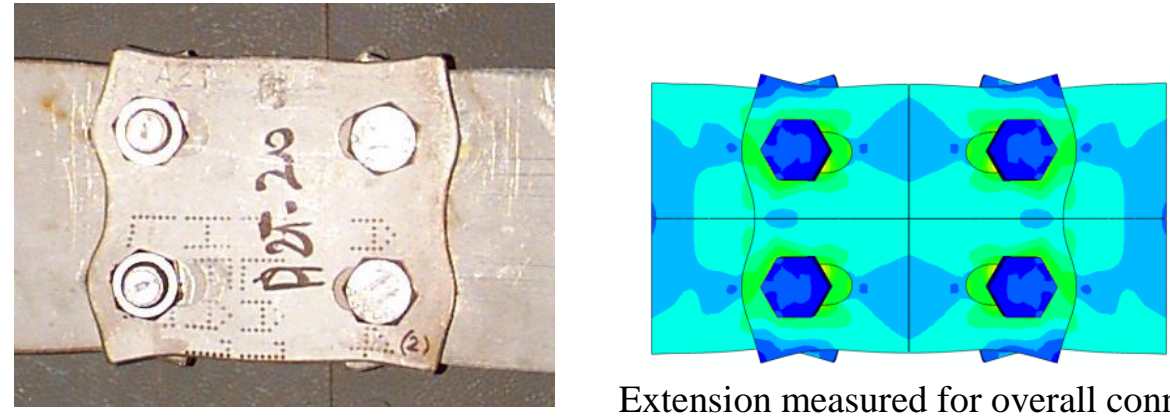

Extension measured for overall connection

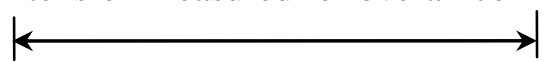

(a) Bearing failure (based on excessive deformation)

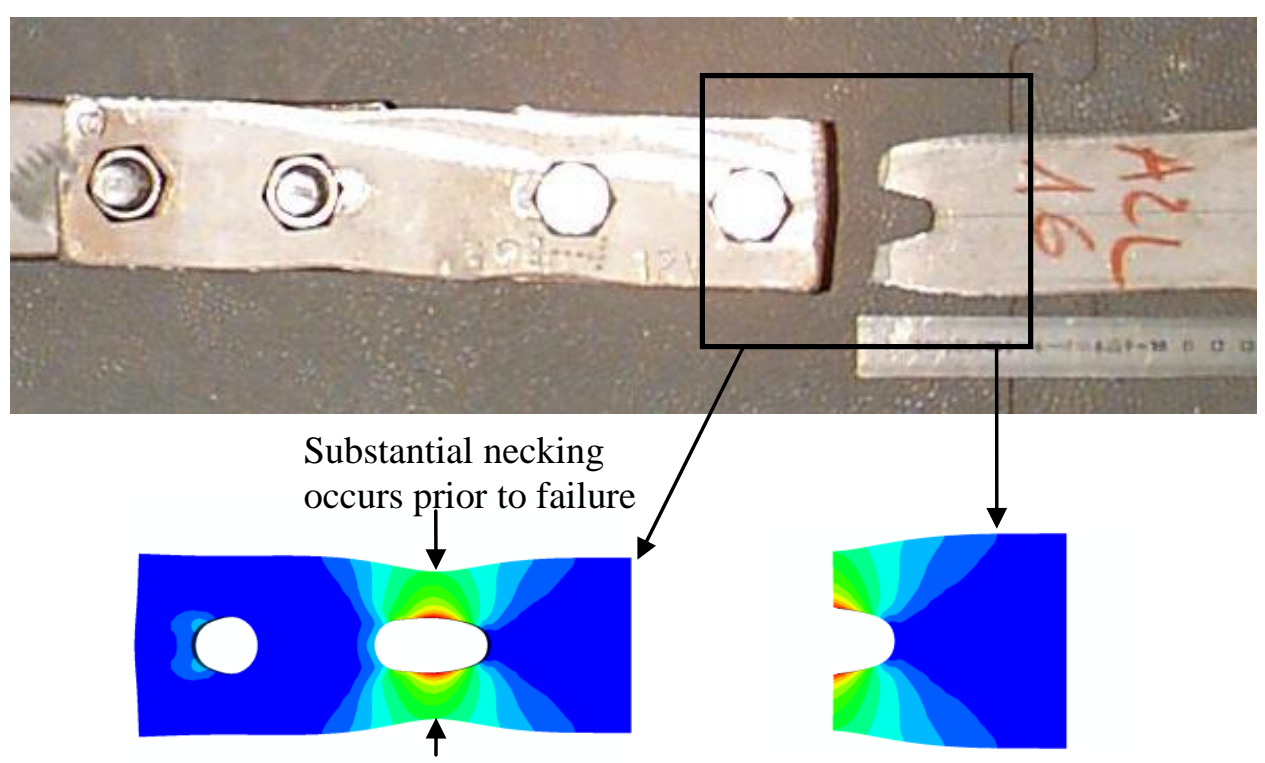

(b) Net section failure

Fig. 5: Comparison between deformed test specimens and numerical models 


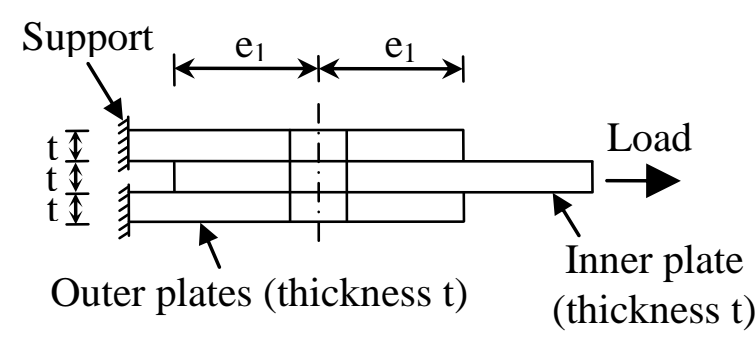

(i) Plan

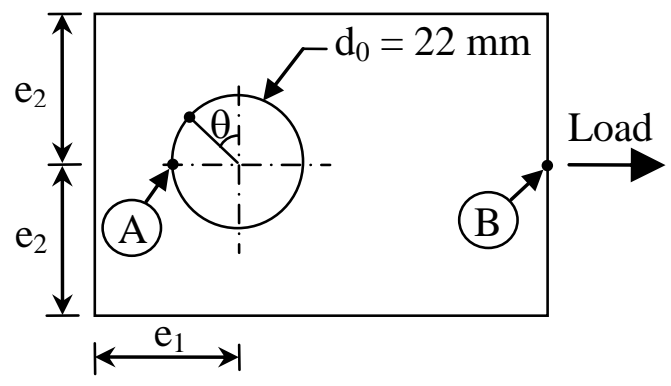

(ii) Side view of inner plate

(a) Double shear connections - inner plate critical

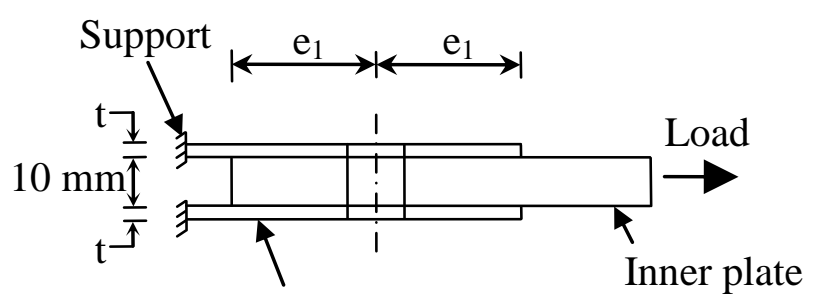

Outer plates (thickness t)

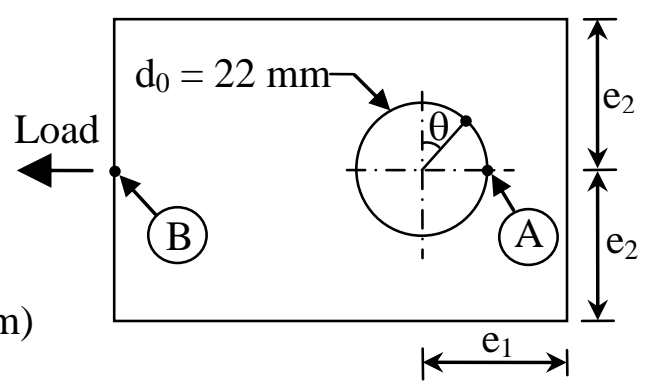

(ii) Side view of outer plate

(i) Plan view

(b) Double shear connections - outer plates critical

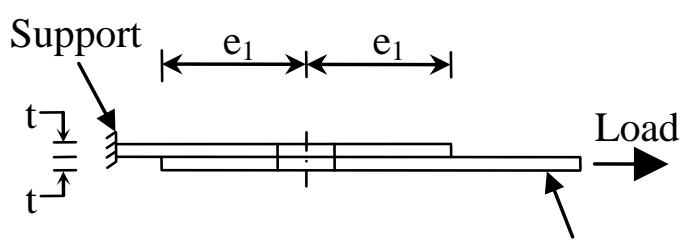

(i) Plan view

Plate (thickness t)

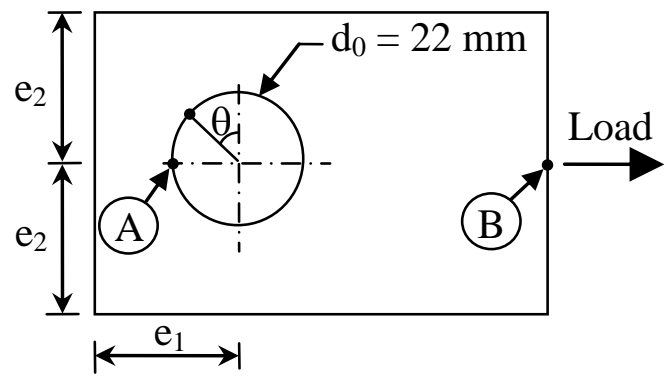

(ii) Side view of plate

(c) Single shear connections

Fig. 6: Definition of $\theta$ and configuration of FE models used in the parametric studies 


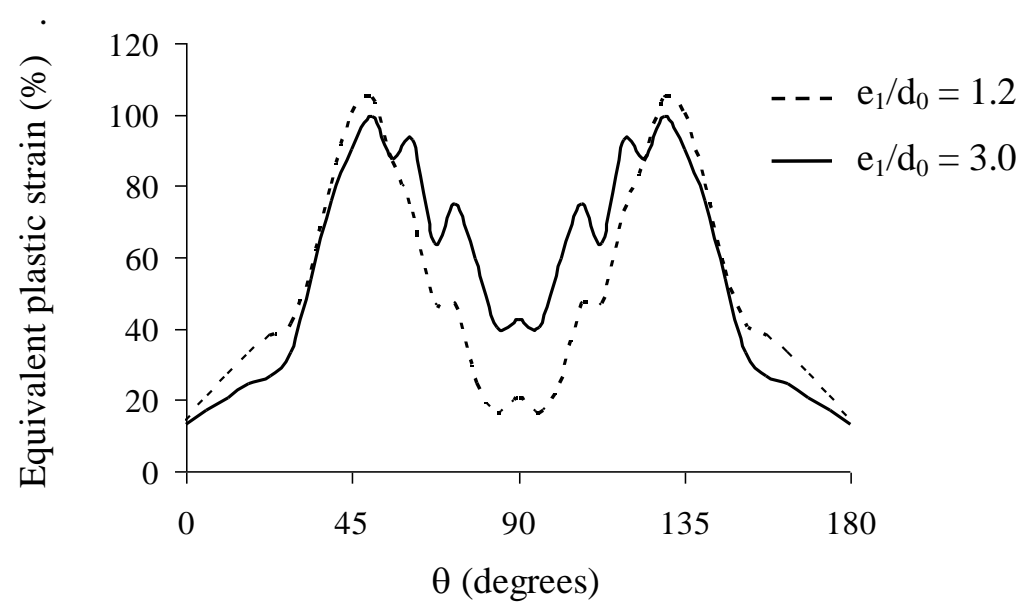

(a) Thick plate connection $(\mathrm{t}=8 \mathrm{~mm})$

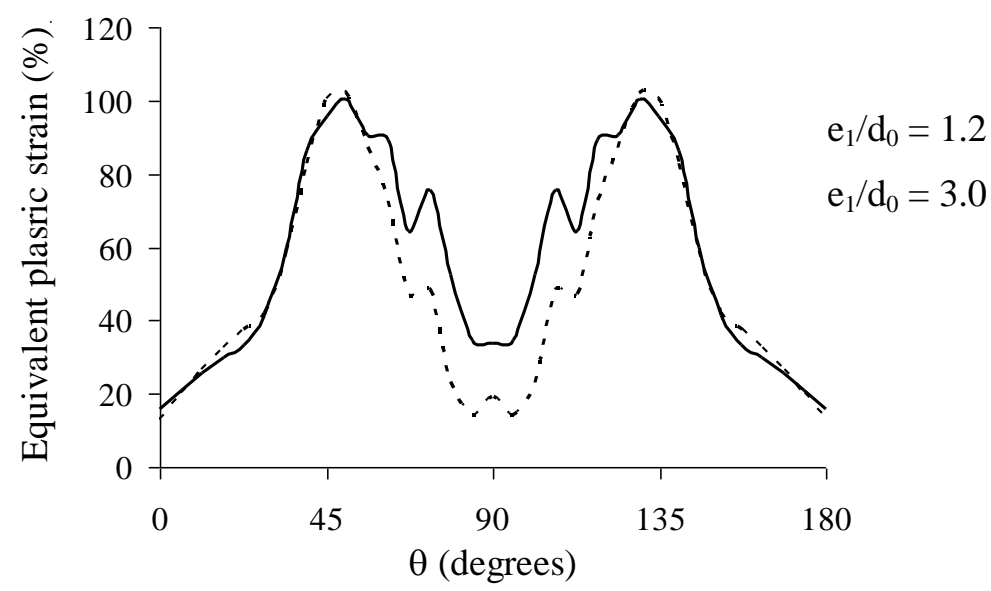

(b) Thin plate connection (inner sheet in double shear connection, $\mathrm{t}=2 \mathrm{~mm}$ )

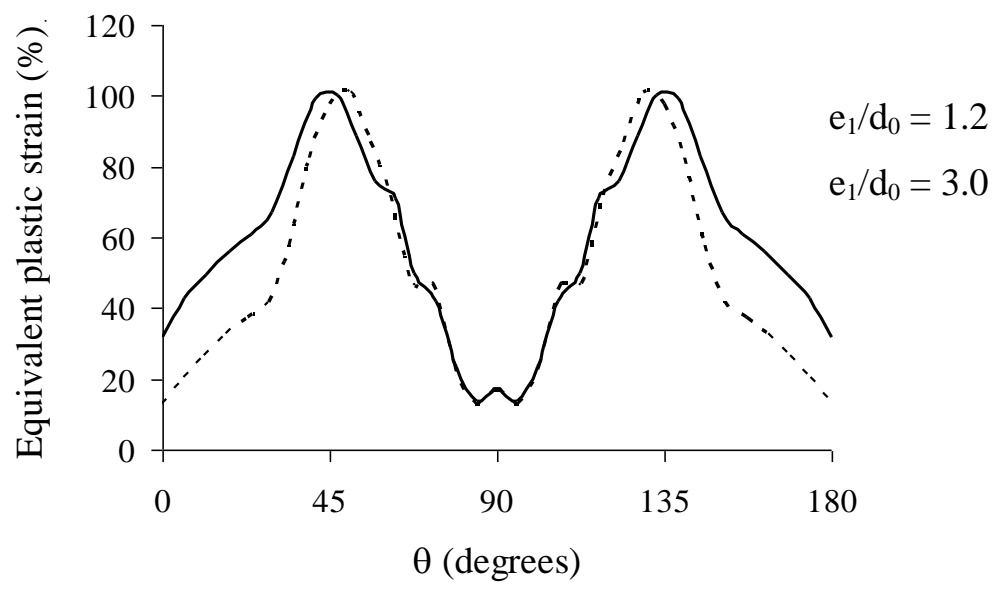

(c) Thin plate connection (outer sheet in double shear connection, $\mathrm{t}=2 \mathrm{~mm}$ )

Fig. 7: Plastic strain distributions in the plate in front of the bolt at failure for different connection geometries 


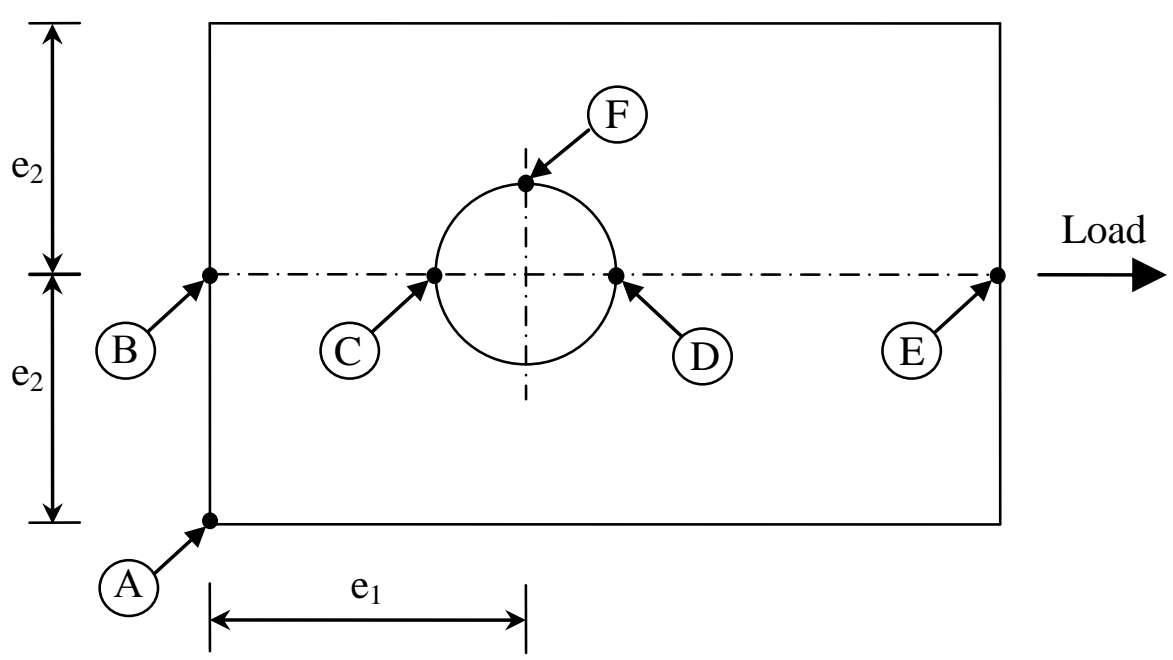

Fig. 8: Reference points assigned to plates in the FE models 


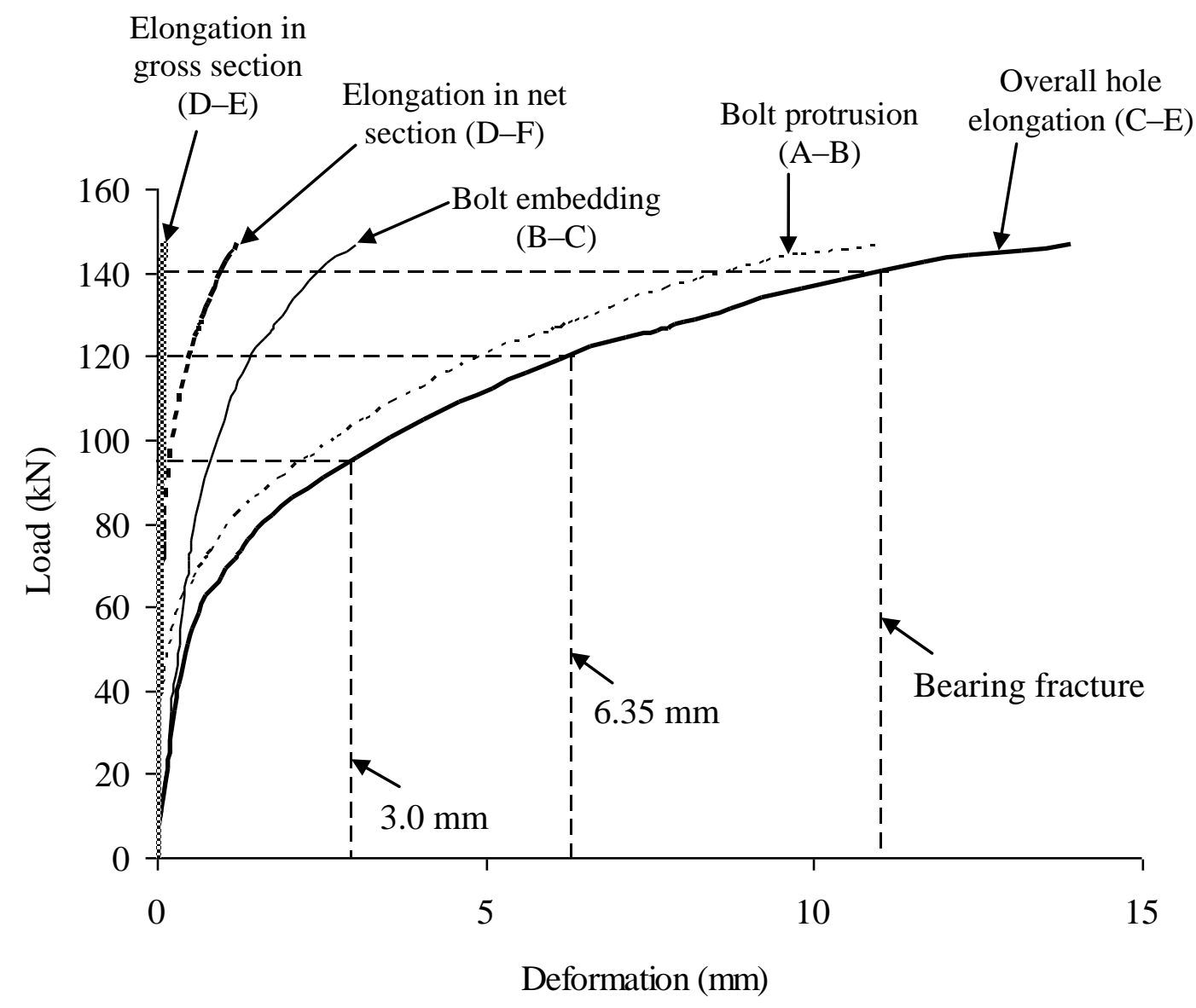

Fig. 9: Components of hole elongation for connection failing by end tear-out (see Fig. 12) 


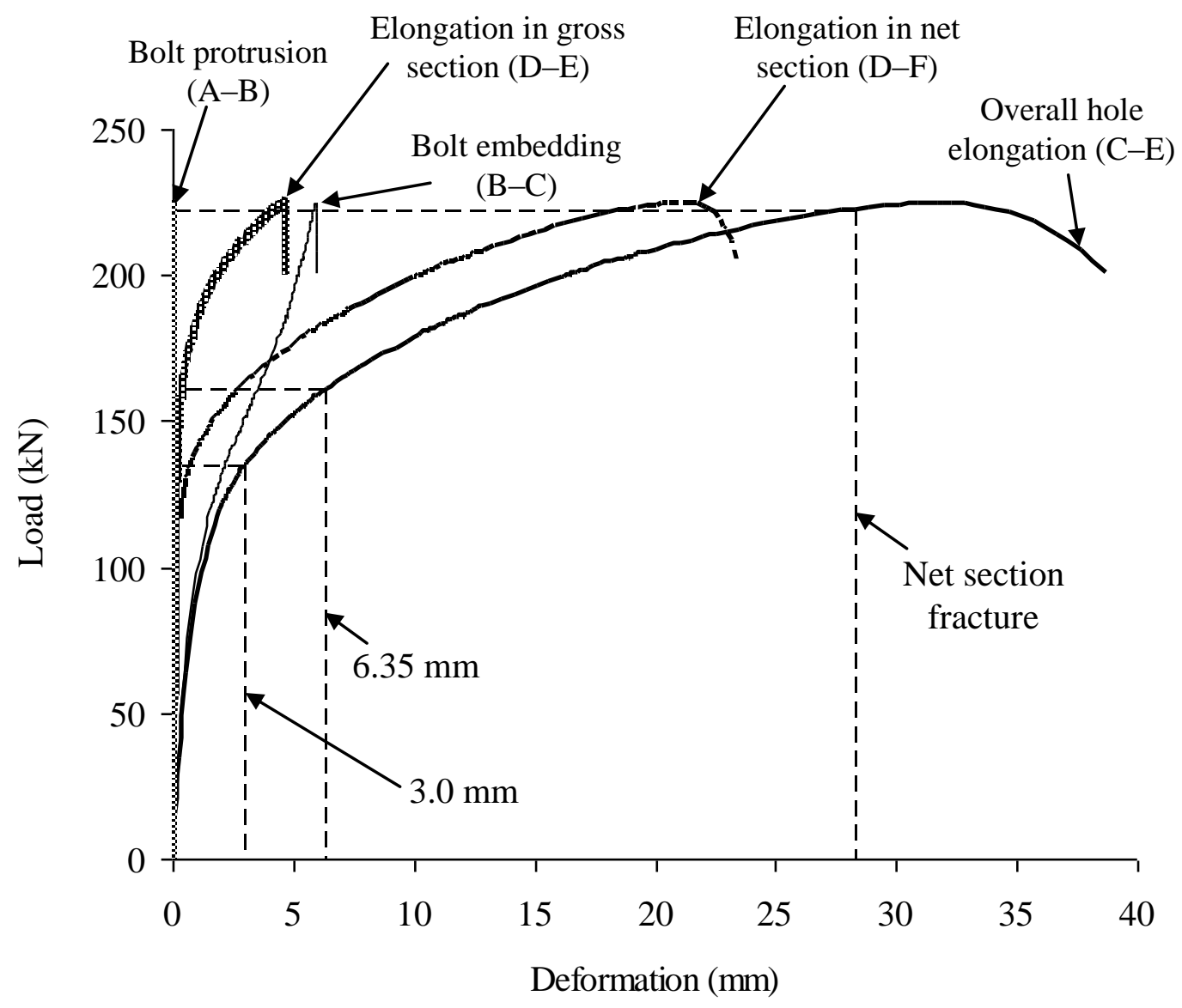

Fig. 10: Components of hole elongation for connection failing in the net section (see Fig. 13) 


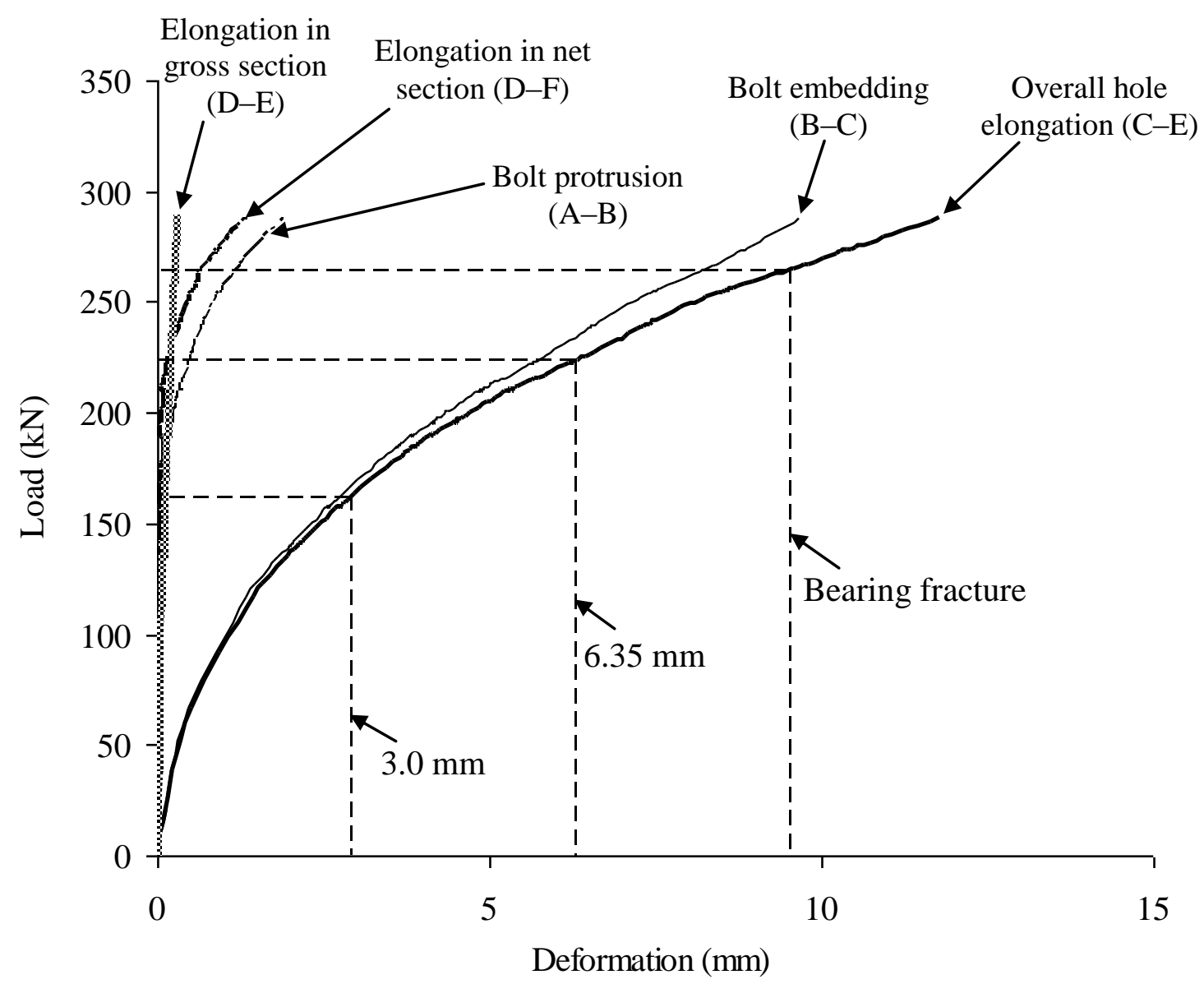

Fig. 11: Components of hole elongation for connection failing by bearing (see Fig. 14) 


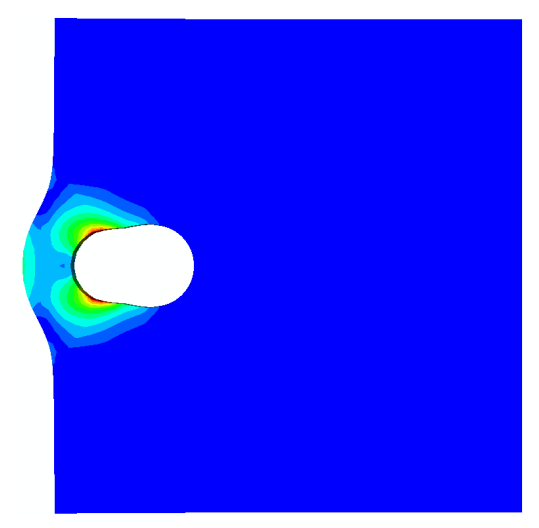

Fig. 12: Deformed shapes from FE models for connections failing by end tear-out

$$
\left(\mathrm{e}_{2} / \mathrm{d}_{0}=3.0, \mathrm{e}_{1} / \mathrm{d}_{0}=1.2\right)
$$

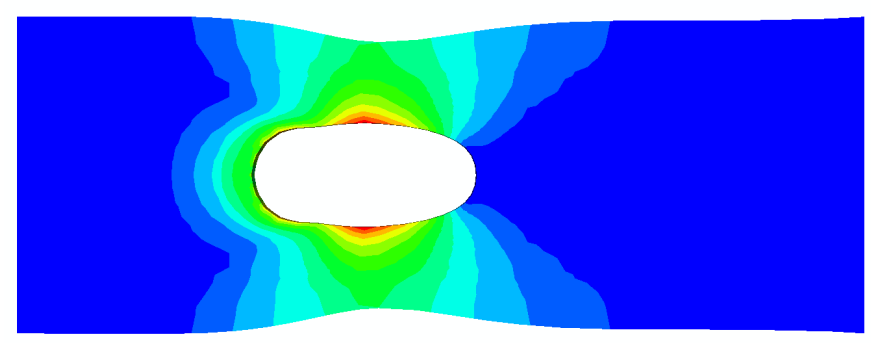

Fig. 13: Deformed shape from FE models for connection failing in the net section

$$
\left(\mathrm{e}_{2} / \mathrm{d}_{0}=1.5, \mathrm{e}_{1} / \mathrm{d}_{0}=3.0\right)
$$

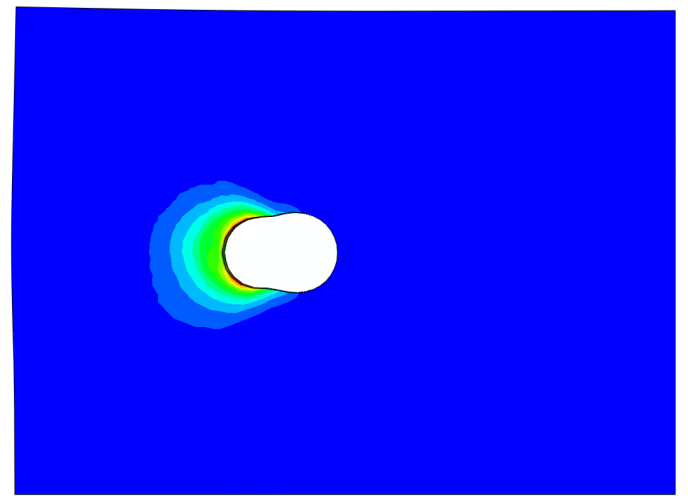

Fig. 14: Deformed shapes from FE models for connections failing by bearing

$$
\left(\mathrm{e}_{2} / \mathrm{d}_{0}=3.0, \mathrm{e}_{1} / \mathrm{d}_{0}=3.0\right)
$$




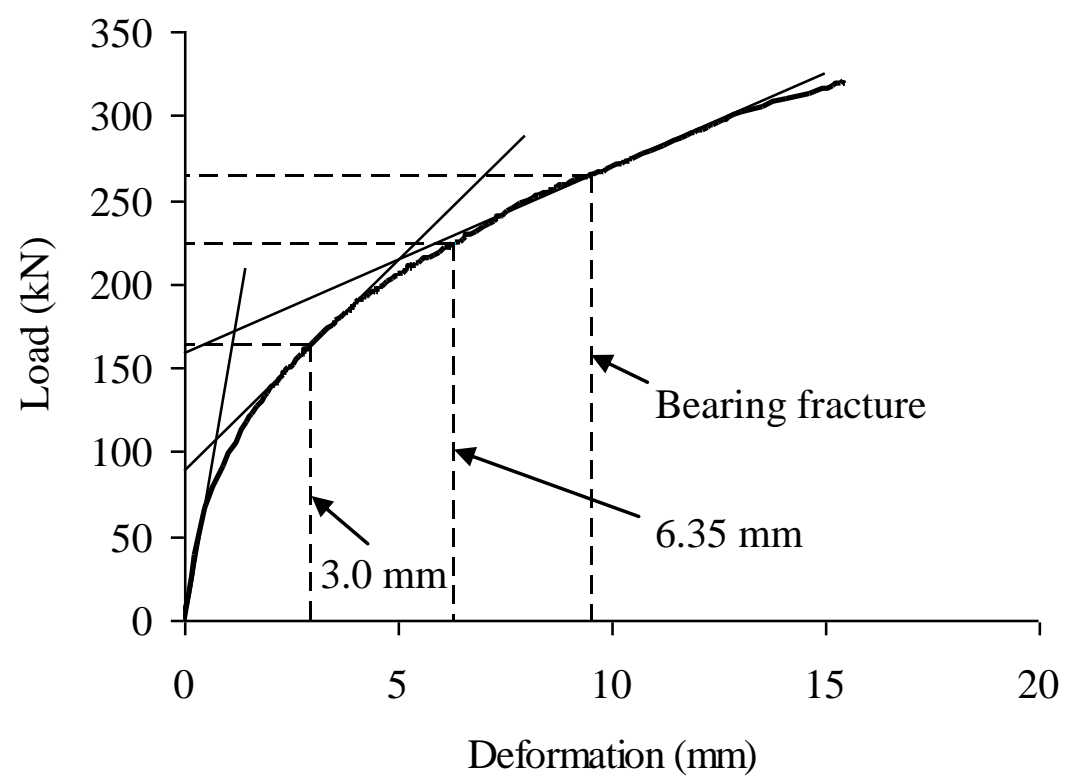

(a) Thick plate connection (thickness $=8 \mathrm{~mm}$ )

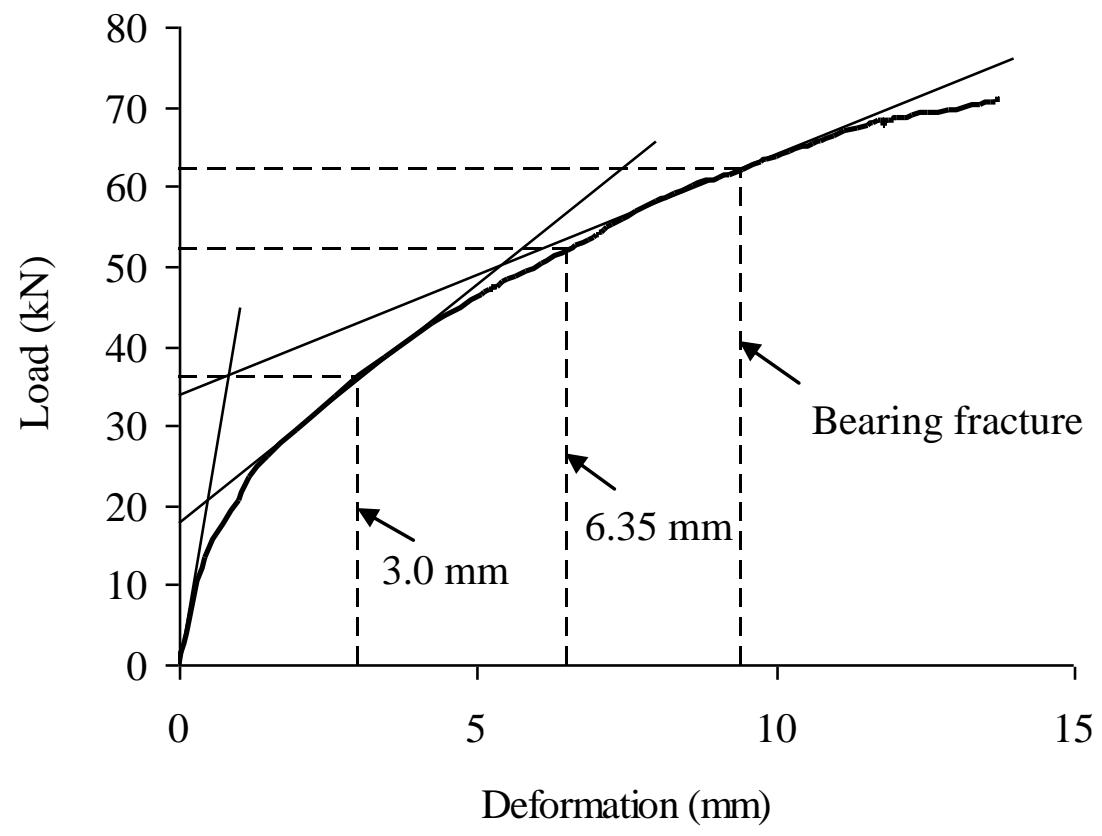

(b) Thin plate connection (inner sheet in double shear connection, $\mathrm{t}=2 \mathrm{~mm}$ )

Fig. 15: Stiffness of stainless steel connection failing by bearing 


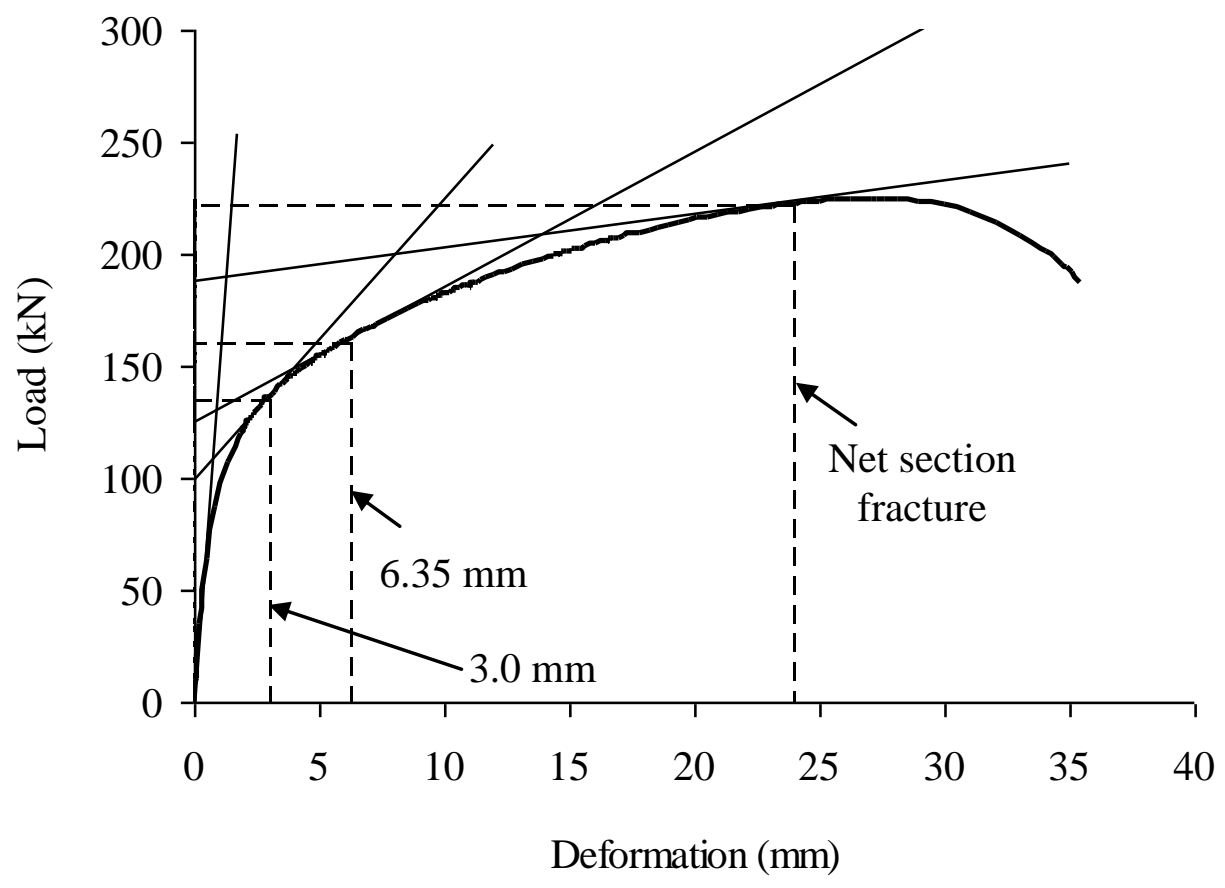

Fig. 16: Stiffness of stainless steel connections failing in net section rupture 


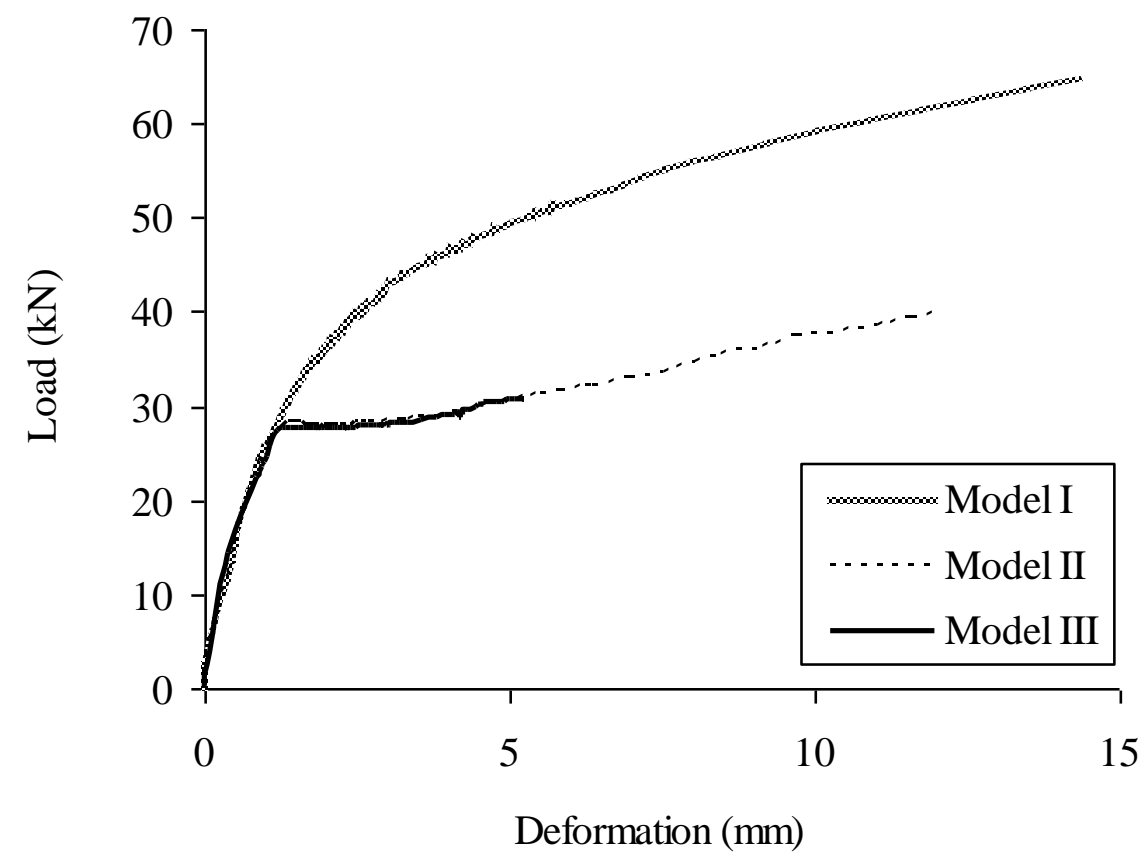

Fig. 17: Comparison between thin sheet connections in single and double shear 


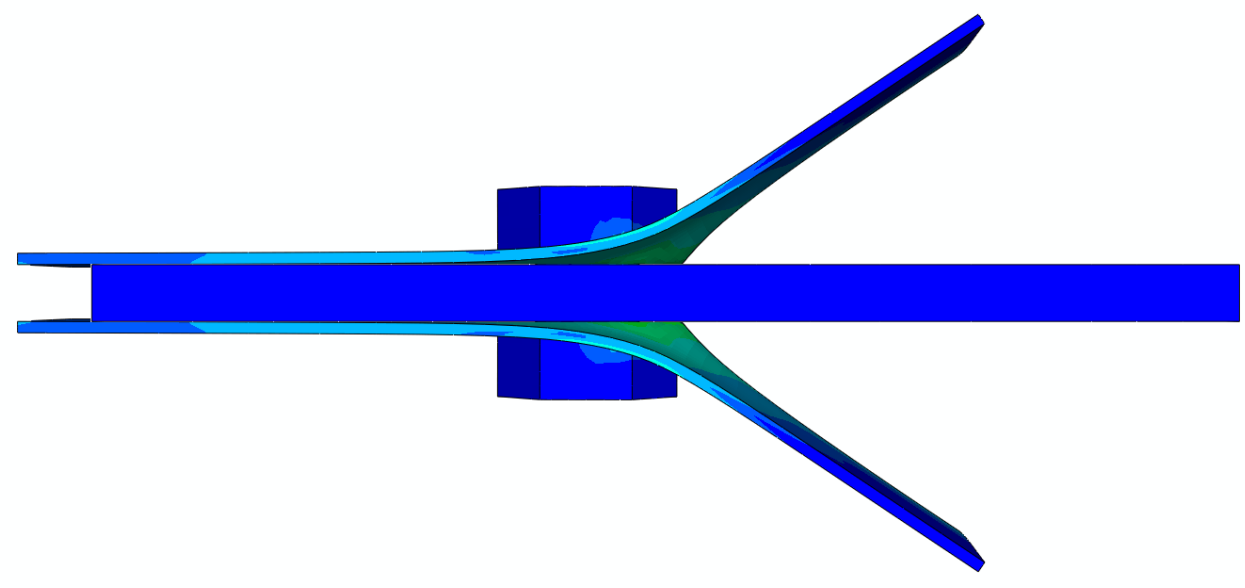

(a) Outer plates in double shear connection (Model II)

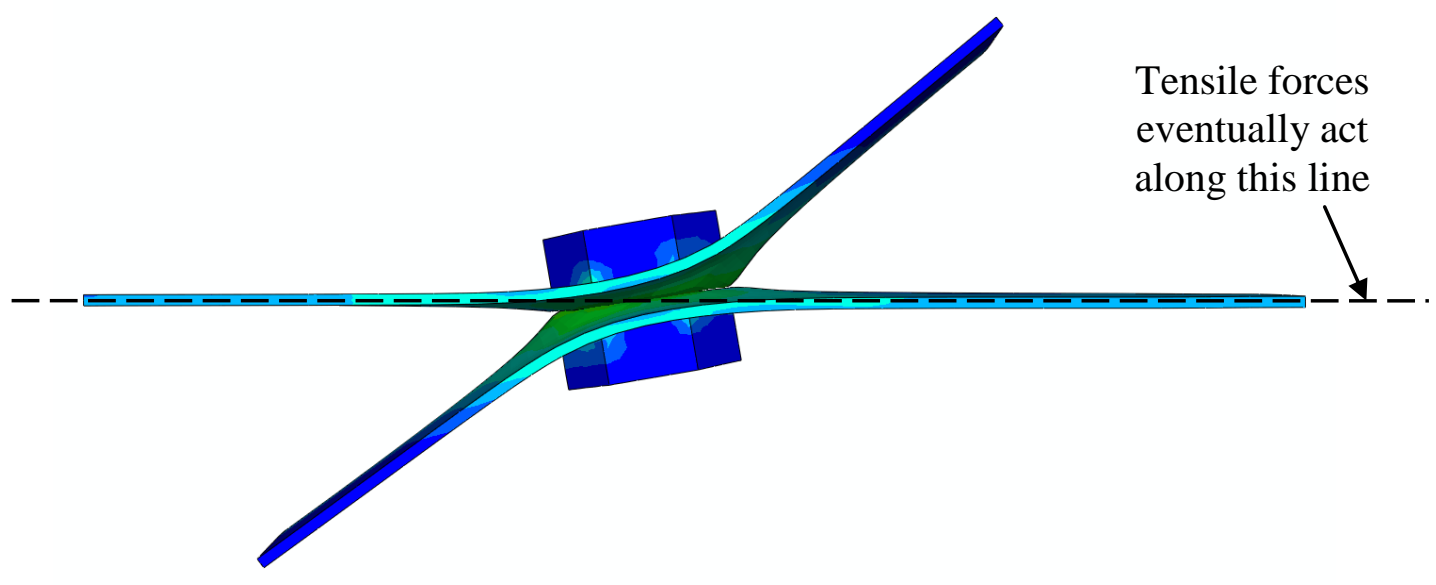

(b) Single shear connection (Model III)

Fig. 18: Deformed shape of connections susceptible to curling and pulling into line 

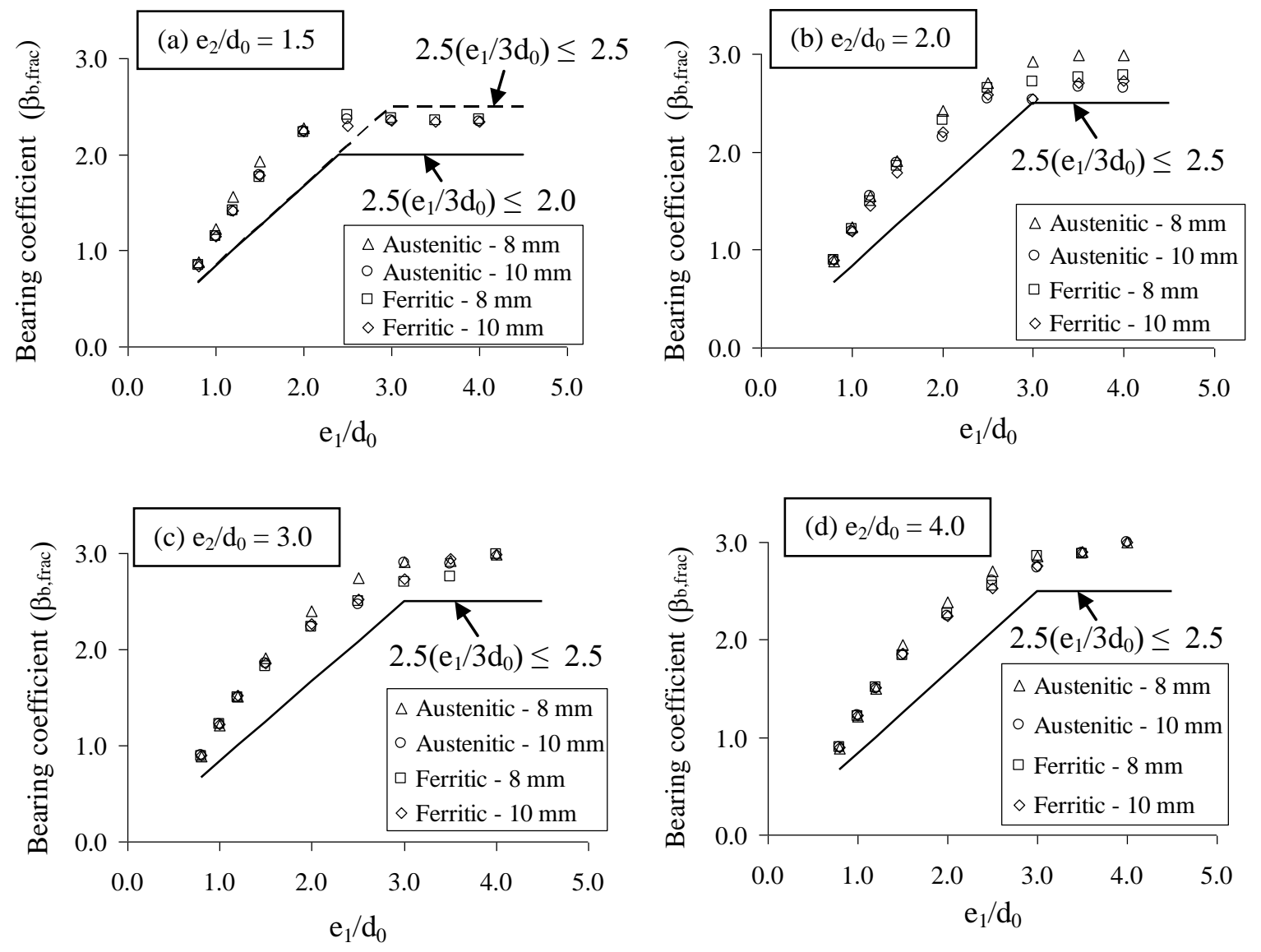

Fig. 19: Bearing coefficient for thick plates $(8$ and $10 \mathrm{~mm})$ from parametric studies by adopting strength criterion 

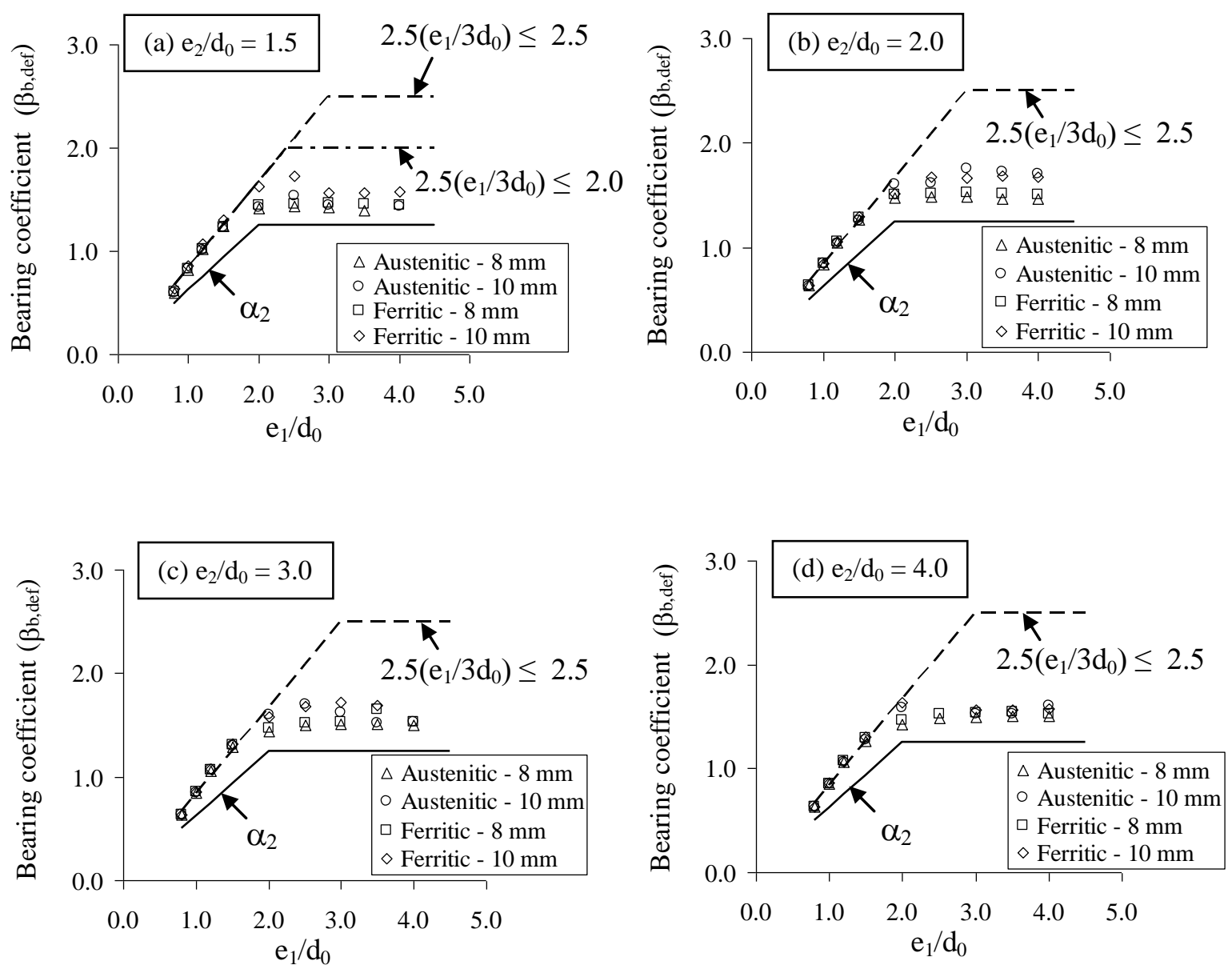

Fig. 20: Bearing coefficient for thick plates $(8$ and $10 \mathrm{~mm})$ from parametric studies by adopting deformation criterion 

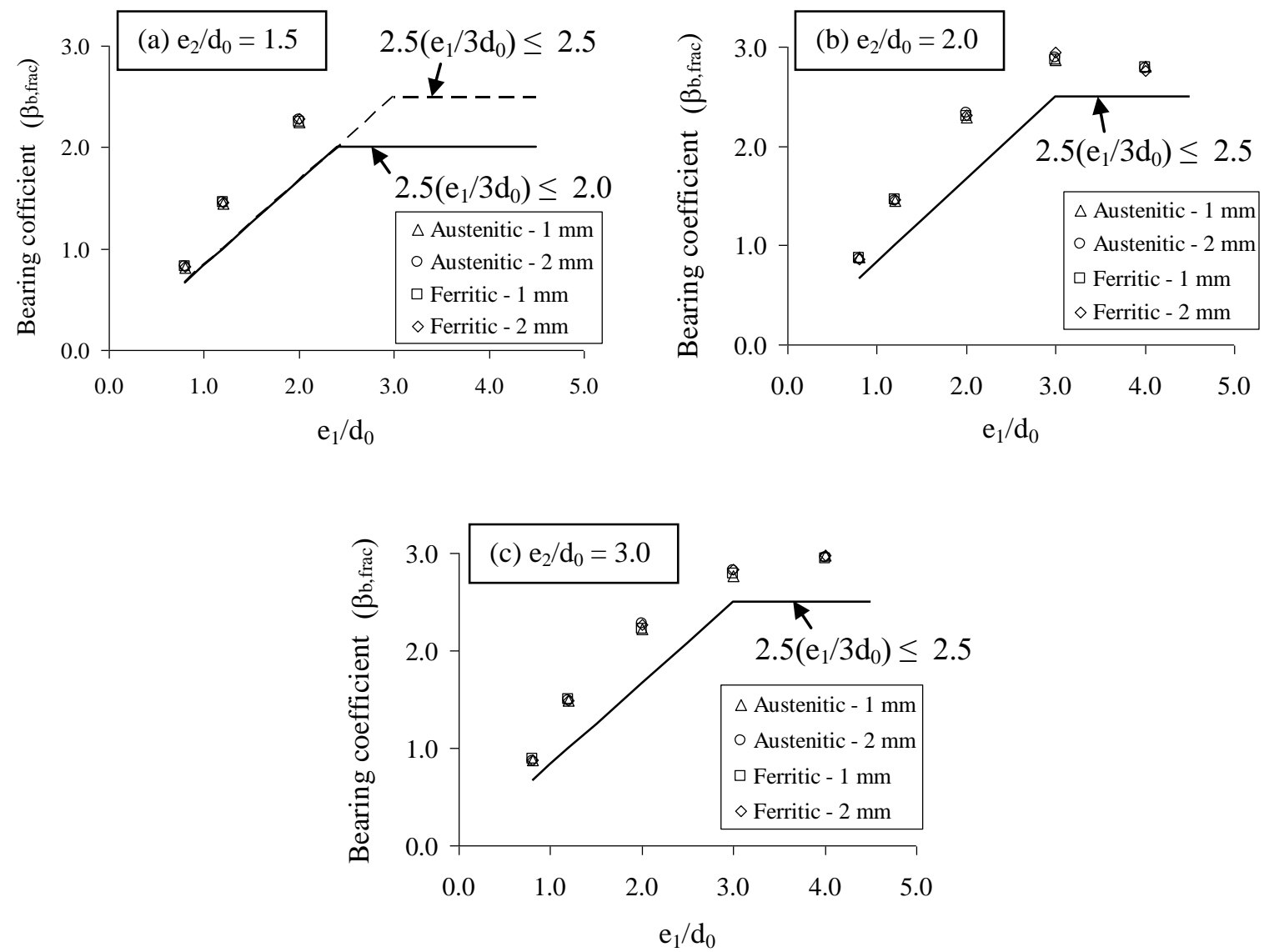

Fig. 21: Bearing coefficient for thin sheets where curling does not occur (1 and $2 \mathrm{~mm}$ ) from parametric studies by adopting strength criterion 

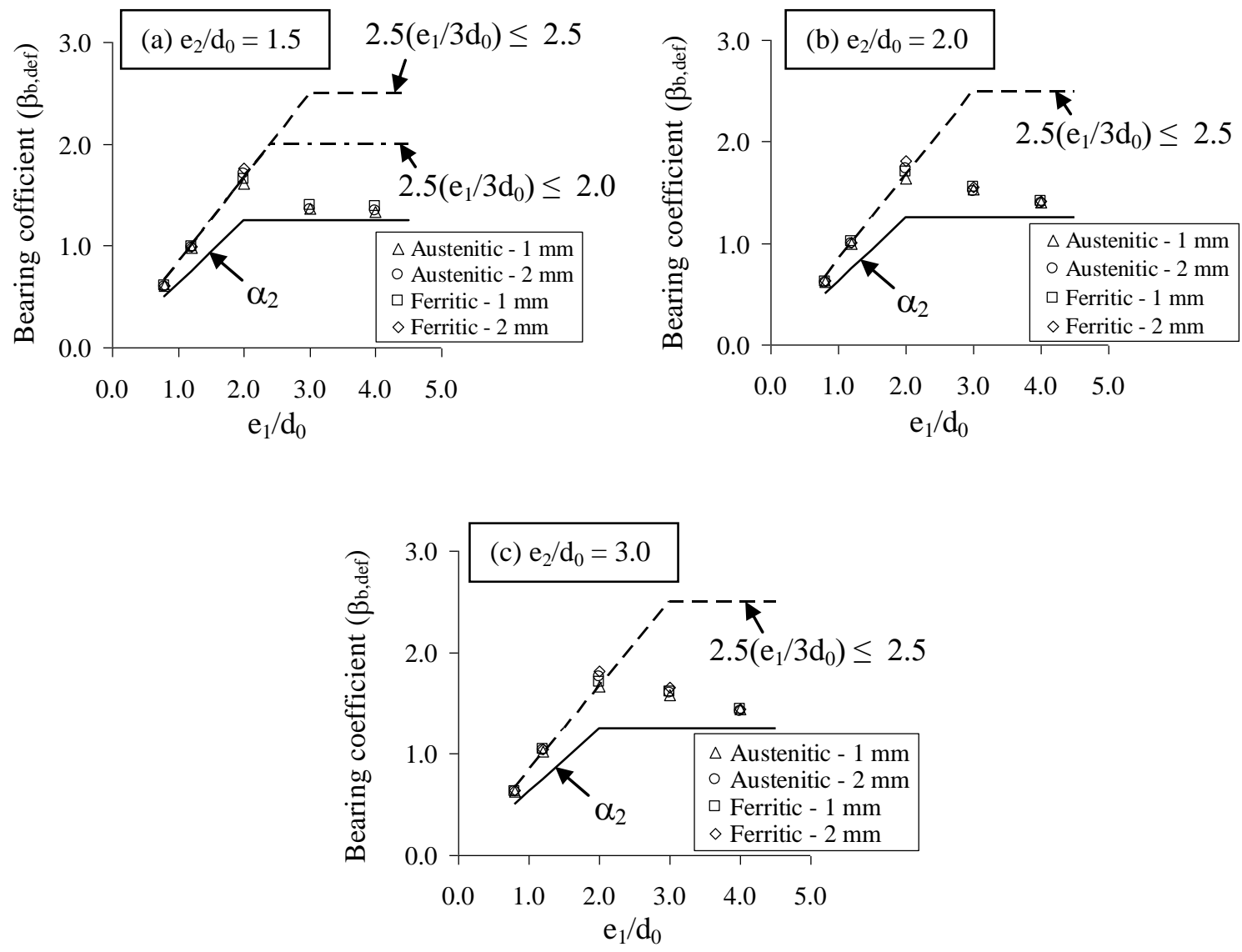

Fig. 22: Bearing coefficient for thin sheets where curling does not occur (1 and $2 \mathrm{~mm}$ ) from parametric studies by adopting deformation criterion 

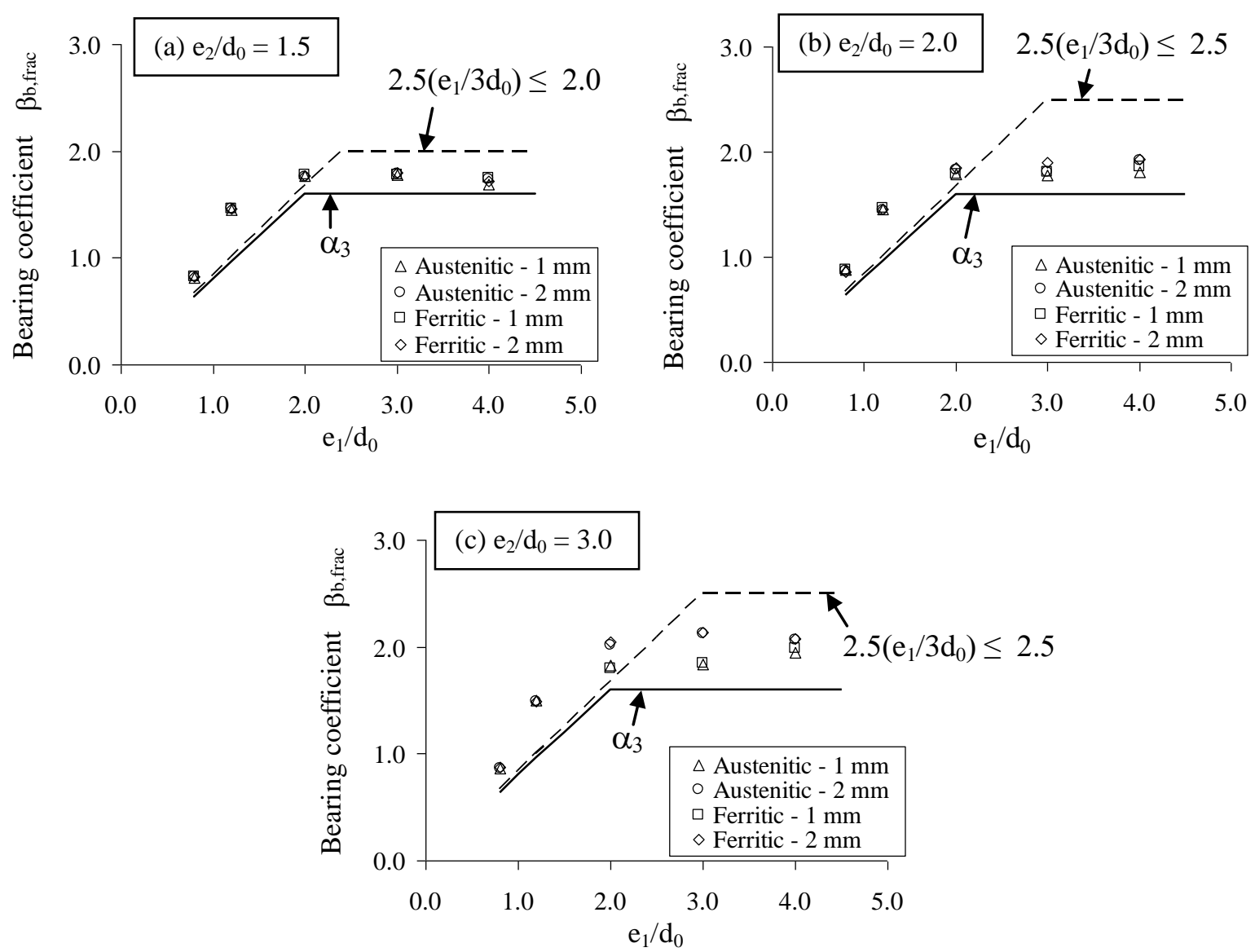

Fig. 23: Bearing coefficient for thin sheets where curling does occur (1 and $2 \mathrm{~mm}$ ) from parametric studies by adopting strength criterion 

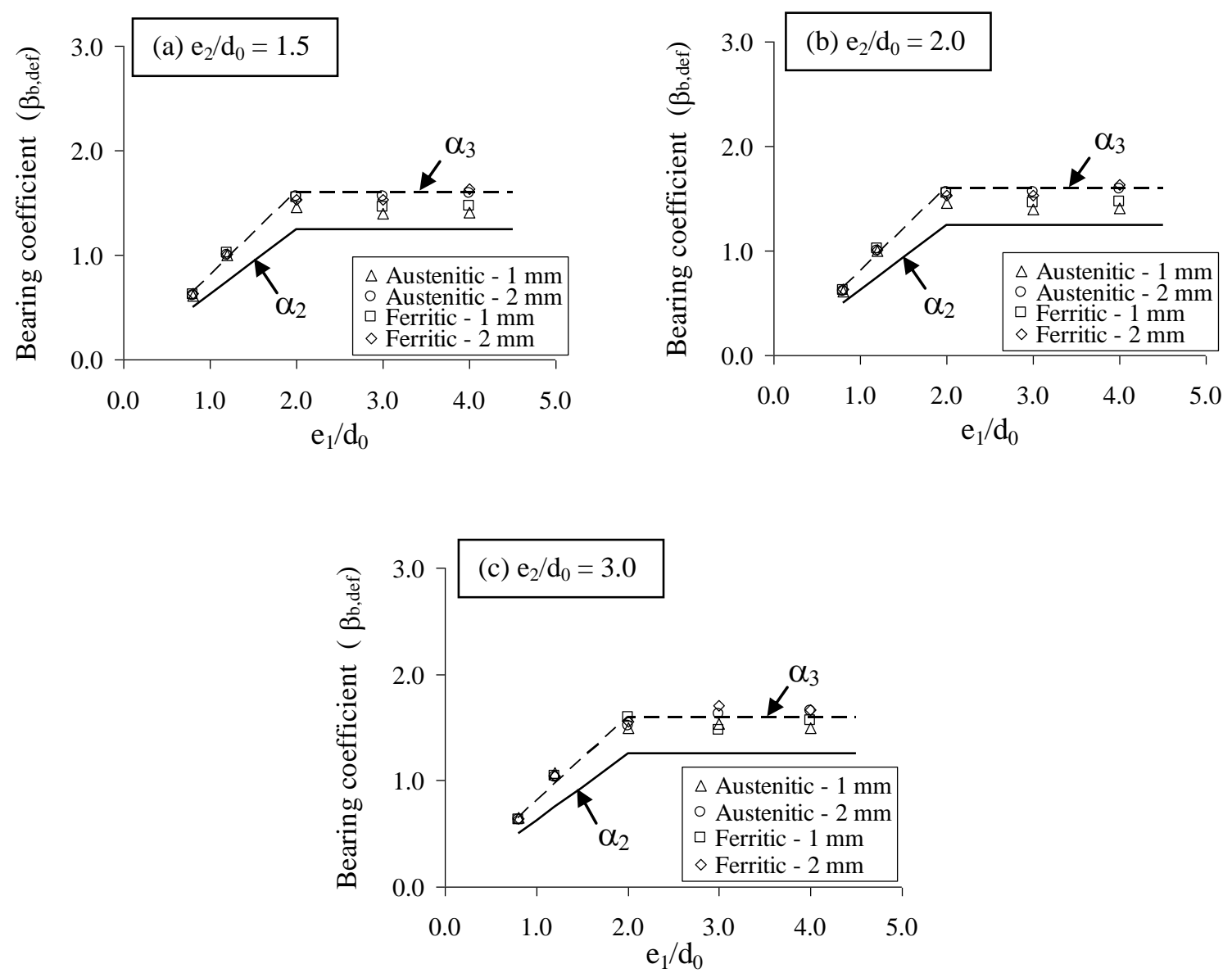

Fig. 24: Bearing coefficient for thin sheets where curling does occur (1 and $2 \mathrm{~mm})$ from parametric studies by adopting deformation criterion 